ANUARIO DE Estudios MEdiEVALES

44/2, julio-diciembre de 2014, pp. 769-805

ISSN 0066-5061

doi:10.3989/aem.2014.44.2.04

\title{
ARTESANOS VIDRIEROS EN MALLORCA. RELACIONES Y CONEXIONES CON EL LEVANTE PENINSULAR (SIGLOS XIV-XV) ${ }^{1}$
}

\section{GLASSMAKERS OF MAJORCA. RELATIONSHIPS AND CONNECTIONS WITH THE EASTERN PENINSULA (14th-15th CENTURIES)}

\author{
Miquel Àngel CAPELlà GALMÉS \\ Universitat de les Illes Balears
}

\begin{abstract}
Resumen: En este artículo se analiza el ciclo productivo del vidrio y los artesanos que en él intervinieron en la Ciutat de Mallorca durante los siglos XIV y XV. También es fundamental fijar las relaciones que se establecieron con Barcelona y otras zonas de la Corona de Aragón, en el marco de la producción y del comercio del vidrio en época gótica. Se estudia, mediante la documentación de archivo, la localización de los hornos, su estructura, así como el origen de las materias primas utilizadas en la fabricación y, finalmente, los modelos de organización y relaciones familiares de los vidrieros.
\end{abstract}

Palabras clave: vidrio; tecnología; talleres; vidrieros; vidrio catalán; Mallorca.

\begin{abstract}
This paper analyses the production cycle of glass, and the artisans who worked it, in the city of Majorca during the 14 th and 15 th centuries. It also studies the relationships established with Barcelona and other areas in the Crown of Aragon for glass production and trade in the gothic period. Based on archival documentation, this paper studies the locations and structure of kilns, the source of the raw materials used in the manufacturing and, finally, the models of organisation and family relations of the glassmakers.
\end{abstract}

Keywords: glass; technology; glass workshops; glass blowers; Catalan glass; Mallorca.

\section{SUMARIO}

1. Introducción.- 2. Localización de los talleres de artesanos vidrieros.- 3. Hornos

y herramientas.- 4. El abastecimiento de materias primas.- 5. El combustible.6. Vidrieros y vínculos territoriales.-7. La organización laboral.- 8. Conclusión.- 9. Bibliografía citada.

1 Abreviaturas utilizadas: $\mathrm{ACM}=$ Arxiu Capitular de Mallorca; $\mathrm{ARM}=$ Arxiu del Regne de Mallorca; Not. $=$ Notaris; RP $=$ Reial Patrimoni; s.f. $=\sin$ foliar. 


\section{INTRODUCCIÓN}

Un taller de vidrio necesitaba para su perfecto funcionamiento toda una serie de redes humanas activas a su alrededor, que se encargaban del suministro de las materias primas, el combustible, la redistribución de las cenizas y los objetos elaborados. Este sistema giraba en torno a una arquitectura modesta, aunque compleja, en la que se desarrollaba la actividad artesanal y que presentaba zonas porticadas y abiertas, con uno o varios hornos, lugares destinados a la preparación de la masa vítrea, almacenes para la madera y los residuos, y un espacio dedicado a vivienda ${ }^{2}$. Esta diversidad se reflejaba necesariamente en el personal vinculado al obrador.

Nuestra intención es caracterizar una parte del ciclo productivo del vidrio en la Baja Edad Media en Mallorca y las conexiones que se establecen con el Levante peninsular: centrándonos en dos aspectos fundamentales, la movilidad de materiales y de artífices ${ }^{3}$.

\section{LOCALIZACIÓN DE LOS TALLERES DE ARTESANOS VIDRIEROS}

La documentación de archivo, así como las numerosas intervenciones arqueológicas realizadas en Mallorca, no han sido demasiado generosas en cuanto a los datos aportados sobre los talleres existentes, que son significativamente más escasos en el siglo XIV que en la centuria siguiente. El número de obradores podría ser mayor, si tenemos en cuenta que conocemos los nombres de vidrieros que compraron materiales o contrataron a artesanos para trabajar con ellos sin que conste el lugar donde ejercían el oficio ${ }^{4}$.

Los hornos, como norma general, se instalaron en el interior de la Ciutat de Mallorca, a excepción de las primeras infraestructuras, que no siguieron este esquema. Las factorías urbanas se caracterizaron por su localización periférica, en zonas poco pobladas y construidas, en ocasiones cerca de la muralla. Esta situación pudo estar determinada por las particularidades de las factorías, que podían implicar un peligro de incendio. Se trataba de lugares de la ciudad en los que convivían diferentes sectores manufactureros

M.A. Capellà, El vidre a Mallorca, pp. 85-162.

T. Mannoni, E. Giannichedda, Arqueología de la producción, pp. 105-108.

4 Uno de los ejemplos más reveladores es el de Francesc Rotlan que a fines del XIV tenía taller propio que no hemos podido documentar (ACM, 14717, s.f.). En el año 1400 vendió una esclava cristiana a un pescador de la ciudad de Barcelona. Sabemos que nombró diversos procuradores, uno de ells "efectuaba funciones comerciales y es probable que le vendiera los productos que él realizaba en Mallorca" (M.C. Riu, La manufactura del vidrio y sus artífices, p. 607). 
con problemáticas similares. Otro factor que condicionó esta ubicación fue el rápido acceso desde el exterior, al encontrarse próximo a alguna de las puertas del recinto fortificado, facilitando el abastecimiento de combustible y de materias primas 5 .

Además, una vez enclavadas en el solar urbano, estas infraestructuras permanecieron fijas con el paso del tiempo, sin cambiar su emplazamiento en la urbe, tan sólo renovando la instalación productiva de manera periódica, en caso de necesidad, debido al deterioro. Por supuesto, esta pervivencia no es una característica exclusiva de este oficio sino que se comparte con ciertos colectivos artesanos, como se ha demostrado con los alfareros ${ }^{6}$. En la mayoría de las ocasiones, los artífices mantuvieron en un mismo espacio, pero separados, la casa y el obrador.

Los primeros vidrieros documentados trabajando en la isla, los hermanos Guillem y Bernat $\operatorname{Roger}^{7}$, se dedicaban a la elaboración de vidrio en la parroquia de Calvià en el año $1327^{8}$. Las prospecciones arqueológicas realizadas en este término municipal no han proporcionado ningún tipo de estructura que se pueda vincular con su tarea. La localización, algo alejada de la Ciutat de Mallorca, tampoco nos debe extrañar, aunque las razones para esta disposición seguro que fueron de diversa índole. Así, podría estar determinada porla presencia de materias imprescindibles para hacervidrio,como por ejemplo las plantas soseras, si bien algunos historiadores se decantan por creer que la causa fue la abundancia de leña ${ }^{9}$. En relación a esta última, es fundamental tener en cuenta que esta villa no se hallaba bajo la jurisdicción real sino de la del Obispo de Barcelona, circunstancia que conllevaba un derecho distinto y que tal vez supondría una mayor libertad en el consumo de combustible ${ }^{10}$. Podemos pensar que uno de ellos sería el mismo individuo que construía un horno de vidrio a tres leguas de Girona en $1331^{11}$. Durante estos años, Guillerm Humbert disponía de una infraestructura, según lo dejan entender dos contratos de aprendizaje que le señalan como maestro. Quizá el taller estaba en la capital, ya que los aprendices tenían que distribuir los objetos por varias

5 M. Bernat, J. Serra, El forn de vidre, pp. 92, 94.

6 M. Barceló, G. Rosselló, Terrissa, p. 195.

7 ARM, RP 1492, f. 108v. La transcripción correcta del linaje es Roger y no Roig (R. Rosselló, J. Bover, Els vidriers de Mallorca, p. 502). Véase: A. Campaner, Cronicón Mayoricense, p. 134; D. Aldeguer, Artesanía del vidrio, p. 9; M. C. Giménez, El vidrio soplado, p. 24.

8 La procuración real les vendió 16 cuarteras de trigo que se comprometieron a pagar después de Pascua (R. Rosselló, J. Bover, Els vidriers de Mallorca, p. 502).

9 M. Bernat, J. Serra, El forn de vidre, p. 103; R. Rosselló, J. Bover, Els vidriers de Mallorca, p. 502.

10 J.B. Ensenyat, Historia de la Baronía.

11 S. Cañellas, C. Domínguez, Els forns de vidre a Barcelona, p. 612. 
localidades mallorquinas ${ }^{12}$. Como en el anterior caso, la ubicación física de este obrador es del todo incierta.

La carestía de leña ocasionada por el alto gasto efectuado por vidrieros y jaboneros provocó la prohibición de sus respectivas actividades por parte del rey Jaume III en el año $1330^{13}$. La medida se puede vincular con el contexto de la época, determinado por la guerra con Génova entre los años 1330-1333, así como con la crisis feudal integral que afectó al Reino Privativo de Mallorca. En relación a este conflicto, hay que indicar que para la conquista de Cerdeña por la Corona de Aragón, Mallorca participó con la construcción de un grupo de veinte barcos ${ }^{14}$. Es probable que esta disposición real supusiera la desaparición de los talleres hasta ahora comentados. En cambio, creemos que no debió afectar a los pintores de vidrieras, ya que empleaban mayoritariamente material importado, sobre todo elaborado en Alemania ${ }^{15}$.

En 1347 se reanudó la actividad artesana. En ese año se había concedido una licencia real a Guillem Barceló, artesano de Barcelona ${ }^{16}$, para levantar un horno de vidrio en el lugar que le pareciera más apropiado, dado que se trataba de una ciudad notable e insigne que no tenía ninguna de estas instalaciones ${ }^{17}$. Funcionó con toda una serie de restricciones en el consumo de leña, que tampoco acabaron por satisfacer a los jurados de la Ciutat de Mallorca. De alguna manera, se derogaba la ordenanza anterior, pero los jurados se interpusieron acusando al vidriero de falsedad en sus papeles. La falta de más datos de archivo y arqueológicos nos ha impedido situar con más precisión este obrador. En 1352 el rey Pere el Ceremoniós concedió a Miquel Bartomeu de Barcelona un nuevo permiso para construir o rehacer otro horno en la capital $^{18}$. Se desconoce la localización exacta de este centro y si se llegó a erigir

La última instalación de esta centuria, que está vinculada a un proceso de normalización de la producción, se documenta hacia 1398. Se trata del complejo de Nicolau Coloma, que estaba cerca a la plaza del Pes de sa

12 R. Rosselló, J. Bover, Els vidriers de Mallorca, pp. 498-500; M.C. Giménez, El vidrio soplado, p. 24.

13 J.M. Quadrado, Privilegios y franquicias de Mallorca, p. 111.

14 P. Cateura, El Regne Esvaït, pp. 45-46.

15 M.A. Capellà, L'activitat de vitrallers, pp. 137-158.

16 No sabemos si se trata de un descendiente o del mismo vidriero documentado en Barcelona entre 1316 y 1340 (S. Cañellas, C. Domínguez, Els forns de vidre a Barcelona, p. 635).

17 E. de K. Aguiló, Industrias mallorquinas, pp. 318-320; A.W. Frothingham, Spanish Glass, pp. 20-21, A. W. Frothingham, Hispanic Glass, pp. 5, 22; D. Aldeguer, Artesanía del vidrio, p. 9; M. Bernat, J. Serra, El forn de vidre, p. 104; J. Ainaud, Cerámica y vidrio, p. 358; M. Sanchis, El arte del vidrio, p. 3; M.C. Giménez, El vidrio soplado, 24; I. Domènech, El vidrio, p. 519.

18 S. Cañellas, C. Domínguez, Els forns de vidre a Barcelona, p. 619. 
palla $^{19}$. Una zona ordenada por la casa del Temple, en una de las puertas de la muralla medieval, caracterizada urbanísticamente por la gran cantidad de huertos que había y la escasa edificación ${ }^{20}$. Sin duda, era el espacio idóneo para el emplazamiento de una infraestructura de estas características, a tenor de las prescripciones imperantes en las ciudades.

Durante la primera década del siglo XV creemos que continuaba activo el horno de los Coloma en el mismo punto, como lo demuestra el hecho de que hasta el año 1412 la sacristía de la Catedral compraba numerosas remesas de piezas al vadrier del Pes della palla ${ }^{21}$. Desde mediados de la centuria, las referencias dejan de mencionar a este obrador, aunque en el año 1482 se pagaron 2 sueldos por un trozo de callejón contiguo al horno del Pes de sa palla $^{22}$. La duda está en si se trata de un topónimo urbano, que aún se mantenía vigente entre la población, o si seguía soplando objetos. En este sentido tan sólo podemos añadir que en 1478 un vidriero vivía en la manzana del Temple, pero sin que se especifique la existencia de un centro productivo ${ }^{23}$.

Otra infraestructura de la que disponemos de noticias dispersas se hallaba en la calle dels Oms, vía adyacente al convento de Santa Margarita (fig. 1). En 1407 Joan Banyeres alquiló a Nicolau Coloma unas casas con corral, in quo nunc est constructum furnum vitrei, por las cuales pagaba 115 sueldos anuale ${ }^{24}$. Con anterioridad, en estas casas había vivido el compañero de profesión Joan Lloreda y su esposa. El alquiler de Coloma puede interpretarse como un traslado del taller desde el Temple o como la ampliación de su actividad. Hoy por hoy, no se puede demostrar que la infraestructura la construyera Lloreda, tampoco hemos podido determinar desde qué momento estaba operativa. Tres años después, Martí Coloma, descendiente de Nicolau, hizo donación de este edificio a Jaume Miralles. Si bien desconocemos qué vidriero o vendedor de vidrio lo regentaba, sabemos que entre 1420 y 1425 estaba activo, ya que se efectuaron varias ventas de vinajeras y otros objetos a la Catedral de Mallorca. En 1474 Jordi Joan de Ruesca, oriundo de Calatayud, estableció las casas con horno de vidrio situadas en la calle dels Oms a Francesc Ros. Parece que no pretendía producir vidrio, de hecho, no consta dicho inquilino en ningún documento relacionado con este oficio. Todo parece

19 Este obrador funcionaba como mínimo desde aproximadamente 1395 (M. Bernat, J. Serra, El forn de vidre, p. 104; R. Rosselló, J. Bover, Els vidriers de Mallorca, pp. 497-498).

20 M. Barceló, G. Rosselló, La ciudad de Mallorca, pp. 194-195.

21 ACM, 1412, f. 42.

22 M. Barceló, G. Rosselló, La ciudad de Mallorca, p. 301.

23 M. Barceló, Ciutat de Mallorca, p. 200.

24 R. Rosselló, J. Bover, Els vidriers de Mallorca, p. 497. La casa confrontaba con la calle mencionada, con el huerto de Marimon Rovira, con el hospicio de Nicolau Sonera y con un callejón sin salida. 
indicar que se trata de la misma manufactura de inicios de siglo, que además nos permite distinguirla de otro obrador, con el que en un principio se podría confundir por estar emplazado en esta zona de la ciudad.

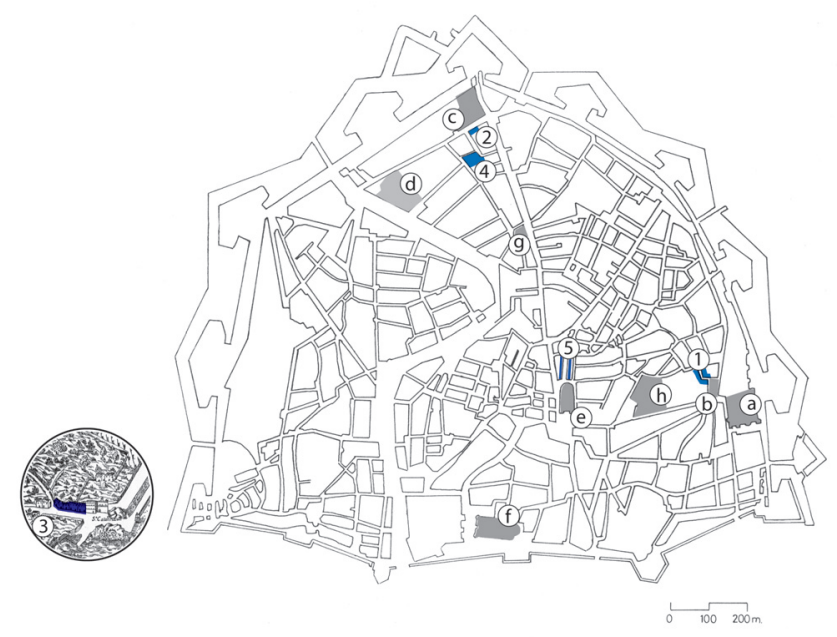

Fig. 1. Localización aproximada de los talleres citados junto a enclaves significativos de la Ciutat de Mallorca: 1: Horno de vidrio del Pes de sa palla, 2: Horno dels Oms, 3: Horno de la Cordelería en Santa Catalina, 4: Horno de los Sala, 5: Calle de la Vidriería; a: El Temple,

b: Plaza del pes de sa palla, c: Convento de Santa Margarita, d: Convento del Carmen,

e: Parroquia de Santa Eulalia, f: Catedral de Mallorca, g: Parroquia de San Miguel, h: Convento de San Francisco.

En 1408 Pere Sala arrendó por el precio de siete libras una tienda y un horno en la plaza de los Cordeleros ${ }^{25}$, que se puede emplazar en el arrabal de Santa Catalina, ya que diferentes referencias de archivo de mediados del siglo XV la sitúan adosada a la fachada posterior del hospital de Santa Catalina (fig. 1) ${ }^{26}$. En la Palma contemporánea, esta instalación se situaría aproximadamente en la manzana delimitada entre las actuales calles de San Magín, Cerdá, Servet y la avenida Argentina.

En una fecha que no podemos fijar, el obrador de la familia Sala se desplazó a intramuros de la ciudad. En concreto, en 1449 ya se menciona la

25 Ibidem, p. 502.

26 M. Barceló, G. Rosselló, La ciudad de Mallorca, pp. 137-138; J. Santaner, Historia del arrabal, pp. 18-19. 
isla de en Sala en la parroquia de San Miguel $^{27}$, denominación que se mantiene en las tallas de 1478 y 1483, como Ylla d'en Sala, vedrier (fig. 1) ${ }^{28}$. En este espacio, en 1478 tenía casa Antoni Sala (III), hijo del homónimo Antoni Sala (II), que había muerto un tiempo antes, a tenor de la misma fuente documental que nos apunta que su viuda residía en la parroquia de Santa Eulalia $^{29}$. El nombre de las manzanas se daba por edificios representativos, por instituciones, por un personaje conocido en el ejercicio de un cargo o profesión, como era el caso, y por tratarse de una persona con un cierto potencial económico. Una de las dificultades principales radica en emplazar con exactitud estos puntos sobre el espacio de la ciudad actual, aunque en esta ocasión, se puede realizar una aproximación con una cierta fiabilidad ${ }^{30}$. Esta factoría está perfectamente ubicada por muchas referencias como la siguiente, relativa a la transacción de una vivienda que confrontaba cum via publica ante dictam cequiam et ex alia parte cum quoddam carrarono (...) versus furnum del vidre et ex alia parte cum domibus ${ }^{31}$. Mucho más precisa es la donación de un huerto en 1511 que señala el vico per quod itur de ecclesia beate Virginis Marie de Carmelo ad furnum vitri qui vocatur lo forn d'en Sala ${ }^{32}$.

Este taller podría estar ubicado en este entorno desde el año 1415, como se deduce de la lectura de los libros de sacristía de la Catedral que computan la compra de objetos al vadrier que està darrera lo Carme $e^{33}$. El monedaje de la parroquia de San Miguel del 1390 no sitúa a ningún maestro en las manzanas limítrofes al convento, ni tampoco en toda la parroquia ${ }^{34}$. Esta zona de la ciudad, cercana a los carmelitas y a la muralla, también se caracterizaba por la presencia de numerosos huertos. La cartografía histórica refleja estos espacios vinculados a las frecuentes inundaciones que sufría el Carmen por el paso del torrente de Sa Riera. Así por ejemplo, en 1443 Bernat Armengol,

27 D. Zaforteza, La Ciudad de Mallorca, vol. I, p. 133; A. Canyelles, Tall per una armada, p. 17.

28 M. Barceló, Ciutat de Mallorca, p. 251.

29 R. Rosselló, J. Bover, Els vidriers de Mallorca, p. 503.

30 La manzana se situaba según una ordenación arbitraria y no lógica según el tasador, anotándola entre la de Santa Margarita y la de la rectoría de San Miguel (M. Barceló, Ciutat de Mallorca, p. 119, 251).

31 ARM, Not. M-241, f. 153r.

32 El huerto era adyacente "ex una parte cum horto honorabilis Cosme Sbert et ex alia parte cum horto Vidal, mercatoris, et ex alia parte cum horto Michaelis Rota, quondam, et ex alia parte cum via publica" (ARM, Not. C-269, f. 185r-v). En 1516 un terreno lindaba con "la travessa del forn de vidre" (M. Barceló, G. Rosselló, La ciudad de Mallorca, p. 386).

33 "Ítem, paguí a vadrier que està darrera lo Carme per tres lantes" (ACM, 1415, f. 65v).

34 El único era Francesc Bertran que vivía en la manzana que iba desde el convento de Santa Margarita hasta la puerta plegadissa de la muralla (M.D. Cabanes, El “morabatí", p. 80; J. Miralles, Corpus d'antropònims, p. 595). 
pelaire, tenía un huerto que colindaba con el de los herederos de Pere Sala, vidriero, y un callejón ${ }^{35}$.

Algunos autores han querido relacionar esta última infraestructura con unos restos arqueológicos de un solar de la travesía de Can Perpinyà que hace esquina con la calle de Can Burgos ${ }^{36}$. Desgraciadamente, la posterior excavación de la parcela con metodología arqueológica no ha facilitado datos relevantes sobre esta industria que permitan afirmarlo con total rotundidad. Sin embargo, aunque las estructuras estudiadas por Margalida Bernat y Jaume Serra no se identificarían con las productivas de un taller, sí es cierto que la localización coincide con el emplazamiento de esta manufactura.

\section{HORNOS Y HERRAMIENTAS}

El ciclo productivo del vidrio requería tres tipos de hornos: el de frita o de fundir, para la elaboración de la sustancia; el de fusión o de trabajo, utilizado durante el afinado del vidrio y para obrar; y el de recocido, en el que las piezas se dejaban enfriar progresivamente. No obstante, el horno de fusión podía ser la única estructura existente al poderse realizar las tres funciones en él ${ }^{37}$.

Un pedido de materiales efectuado en 1394 por Nicolau Coloma a Julià Martí, que tenían una sociedad en común, permite conocer bastante bien el carácter de su taller. El único horno que tenía era de cinco bocas con el mismo número de crisoles en su interior, y además contaba con otros cinco en el exterior $^{38}$. Entre las herramientas encargadas destacan los seis marbras ferri, una plancha plana, en origen de mármol, sobre la que se rotaba la caña con una posta de vidrio, para homogeneizarla y desarrollar a continuación más manipulaciones del objeto ${ }^{39}$. También se computan 6 moldes de plomo y cobre. El primero de ellos era un mollo gros de plom ad mollandum barrallos, destinado a

35 M. Barceló, G. Rosselló, La ciudad de Mallorca, p. 362, 455.

36 M. Bernat, J. Serra, El forn de vidre, pp. 92-101; M. Barceló, G. Rosselló, La ciudad de Mallorca, p. 385.

37 Las excavaciones arqueológicas realizadas en la ciudad de Palma no nos han proporcionado ningún resto de estructura material de un horno. Algunos de los estudios más completos sobre estas instalaciones, utilizando fuentes arqueológicas e iconográficas, que nos han servido para interpretar la documentación escrita son: A travers le verre, pp. 107-117; R. J. Charleston, Glass furnaces, pp. 9-25; D. Foy, Le verre medieval, pp. 141-170; D. Stiaffini, Il vetro nel medioevo, pp. 41-67. Para el vidrio en al-Andalus véase: P. Jiménez et al., Les ateliers urbains de verriers de Murcia, pp. 433-452 y P. Cressier (ed.), El Vidrio en Al-Andalus.

38 El crisol es uno de los principales indicadores de la existencia de talleres, aunque en ocasiones la gran cantidad de fragmentos no pueden reconstruirse como pasó con los materiales de la excavación del horno de Sant Fost de Campsentelles (A. Oliver, El taller, p. 387).

39 Progresivamente se sustituyó por bronce y hierro (C. Moretti, Glossario, p. 53). 
la creación de piezas grandes, y otro de ellos serviría para ornamentar botellas con decoración en relieve, similar a un panel de abeja o a una piña ${ }^{40}$. Prácticamente un siglo después, en 1482, un obrador posterior tenía como mínimo tres bocas, según consta en el arriendo que se hizo en aquel momento ${ }^{41}$.

Un contrato de 1514 nos es útil para conocer otras cláusulas relativas a la provisión de materiales para el funcionamiento de una infraestructura. Así, se menciona la obligación de la propietaria de aportar "sólo" dos fusores al inicio de cada uno de los dos años de arrendamiento del obraje, mientras que el arrendatario se reservaba la opción de poderlos seleccionar ${ }^{42}$. Es evidente que se trata de una disposición importante por diversas razones. Una de ellas es que, a diferencia de lo que ocurre en otros hornos, nos indica que los crisoles no se elaboraban en el taller, constituyendo un indicio claro de su importación. Una segunda apreciación es que debían encontrarse en el mercado varias calidades de crisoles, o como mínimo, que había diferentes tipos, a nivel de forma, de dimensión y de función ${ }^{43}$. Una tercera cuestión es que creemos que el número de ellos citado nos fija la cantidad mínima indispensable para activar su trabajo. Es por esta razón que el documento notarial especificaba que si para el buen funcionamiento se necesitaban más, debían ser adquiridos por el arrendatario. El modo de producir forzaba a tener más de un $\mathrm{crisol}^{44}$, sobre todo si se hacían piezas de vidrio con aplicaciones de hilos de color sobre una masa incolora ${ }^{45}$.

\section{EL ABASTECIMIENTO DE MATERIAS PRIMAS}

La documentación de archivo, las fuentes bibliográficas, la arqueología y la arqueometría revelan los múltiples ingredientes empleados en la composición del vidrio ${ }^{46}$. En ocasiones, la masa vítrea podía comprarse ya

40 ACM, 14701, s.f.

41 R. Rosselló, J. Bover, Els vidriers de Mallorca, pp. 496, 505.

42 "puxau triar a vostre pleer" (ARM, Not. C-317, ff. 38v-40r).

43 Se recomendaba el uso de tierras selectas en su elaboración debido a la alta temperatura para la fusión del vidrio, aspecto que podía obligar a su importación ante la carencia de arcillas adecuadas, aunque el reciclaje de estos recipientes también era factible (D. Foy, Recyclages, p. 275).

44 El estado fragmentario de estos materiales en muchas ocasiones no permite reconstruir sus perfiles completos. En este período serían de forma troncocónica, los mayores con una altura media entre 16-24 cm, y los menores inferior. Para un estado de la cuestión: R. Chambon, Esquisse de l'évolution, pp. 115-117, À travers le verre, pp. 92-93, D. Stiaffini, Il vetro nel medioevo, pp. 73-74.

45 Un ejemplo lo tendríamos en 1491 en un contrato de alquiler en un horno de Granollers del Vallès, en el que se especifica que podía "tenir morterets en el forn per fer tots els colors que necessitàs" (J. Gudiol, Els vidres catalans, p. 40).

46 La sílice supondría entre un 59 y $75 \%$, los fundentes sódicos, entre un 15 y $20 \%$ y el óxido de calcio o magnesio un 10 o $20 \%$, en una fórmula genérica a la que se sumarían otros 
elaborada, facilitando el ciclo productivo del taller de recepción, aunque sea un modelo más propio de la Antigüedad, siendo residual en la Baja Edad Media $^{47}$

La sílice constituye el componente fundamental en la fabricación del vidrio, localizándose en la naturaleza bajo diferentes formas con un mayor o menor grado de pureza: arena, cuarzos, sílex, gres... ${ }^{48}$ Se trata de un elemento abundante, de fácil acceso y, consecuentemente, barato. La provisión del mineral se realizaba en la parte norte de la isla de Mallorca, en concreto en la zona de Banyalbufar, en la Sierra de Tramuntana. Son diversos los datos que permiten confirmar está dinámica, por ejemplo, en 1413, el maestro Nicolau Coloma tenía alquilada una alquería en la misma ubicación, mientras que en 1507 se prohibía la extracción irregular de piedra de vidrio ${ }^{49}$. El suministro continuado desde esta comarca se mantuvo hasta finales del XIX, siendo un indicador común con otros territorios europeos ${ }^{50}$, como es el caso de Palau del Vidre entre los siglos XIV y XVI ${ }^{51}$.

El fundente utilizado en la producción de la masa vítrea se conseguía con la quema de plantas barrilleras, presentes en las franjas costeras mediterráneas. La referencia más antigua en la Corona de Aragón es la autorización concedida por el prior de Poblet al vidriero Guillem en el año 1189 para recolectar hierbas ${ }^{52}$. El proceso de elaboración de la sosa, relativamente complejo, se conoce a la perfección gracias a textos de mediados del XVI y fines del XVIII, comprobándose idéntico modus operandi en esta actividad artesanal ${ }^{53}$.

Las primeras noticias que insinúan la fabricación de sosa son del siglo XIV ${ }^{54}$. En 1346 el gobernador de Mallorca envió una carta al de Menorca para que impidiese la confección y el comercio de cenizas. Un año después, una carta real vuelve a mencionar las cenizas del Reino de Mallorca para ja-

ingredientes muy difíciles de computar que se podían incorporar de manera accidental ( $\grave{A}$ travers le verre, p. 33).

47 D. Foy, Technologie, pp. 147-170.

48 M. Philippe, Naissance de la verrerie, pp. 111-113.

49 T. Vibot, Son Bunyola, pp. 108-109; R. Rosselló, J. Albertí, Història de Banyalbufar, p. 147.

50 M.A. Capellà, El vidre a Mallorca, pp. 89-92.

51 D. Foy, Le verre medieval, pp. 30-31.

52 H. Amouric, D. Foy, Notes sur la production, p. 161.

53 A. Gil, Explotación y cultivo de las plantas barrilleras, pp. 453-478; M.E. García, Carta sobre el cultivo, pp. 1-11; H. Amouric, D. Foy, De la salicorne, pp. 44-52.

54 La barrilla, Salsola soda L., es una planta de la familia de las quenopodiáceas rara en Mallorca, que crece en lugares pantanosos del Puerto de Andratx y de la bahía de Alcúdia. En cambio, la barrilla borde, Salsola kali L., es muy abundante en la costa. Una tercera variedad sería la Salsola vermiculata $L$. , conocida entre otros nombres como Sosa blanca (F. Bonafé, Flora de Mallorca, vol. II, p. 109). 
bón y vidrio ${ }^{55}$. A inicios del XV, se otorgan algunas licencias concernientes a la recolección de barrilla. En 1406 se recogía del islote de Moltó, y la Procuración Real recibía la cantidad de siete sueldos y seis dineros del maestro Nicolau Coloma ${ }^{56}$. En 1410, el mismo artesano tenía permiso para recolectar la de la isla Mayor de los mares de la Porrassa ${ }^{57}$. Bastantes años después, en 1463 , Antoni Sala recibía autorización para cortar hierbas en el islote de delante la playa de Santa Ponça ${ }^{58}$. Esta licencia se le renovó por otros diez años ya que nadie había mostrado interés por el señorío de este territorio. En los tres casos parece que se trata de la recogida en estado salvaje y no de cultivo, debido a las dimensiones reducidas de estos islotes.

Otro lugar de donde se extraían hierbas para hacer jabón y vidrio era Cabrera $^{59}$, un archipiélago en el que se localizan varias especies útiles para la industria. Además, por su extensión, permitiría un rendimiento mayor que los enclaves citados hasta el momento. Un caso de esta actividad se dio en 1482, cuando Bernat Berard firmó capítulos con Pere Armengol, Antoni Sala, Gabriel Guasch y Miquel Tomás relativos al alquiler de la isla por un período de cinco años. Los cuatro anteriores se responsabilizaron de cuidar del castillo de la bahía de Cabrera, a cambio de la mitad de las ganancias conseguidas con la venta de los rebaños, la leña y las cenizas. El interés de los vidrieros por Cabrera se mantuvo a inicios del XVI, cuando en 1510 Jaume de Berard, propietario, y Bartomeu Ribers, vidriero, formaron una compañía destinada a la explotación durante tres años de los recursos de la isla. Por todo ello, los dos socios se comprometieron a tener alquilados y alimentados cuatro hombres, a aportar asnos, burros y el instrumental necesario, así como arrendar tiendas y encargar fletes para llevar la leña y otros productos a la Ciutat de Mallorca ${ }^{60}$.

Es cierto, como nos han hecho observar Ramon Rosselló y Jaume Bover, que el aumento de la productividad de los talleres mallorquines durante la segunda mitad del siglo XV y, por otra parte, el supuesto déficit y falta de calidad de la sosa mallorquina, y por extensión en las Baleares, provocó la

55 R. Rosselló, J. Bover, La fabricación de la sosa, pp. 28-29.

56 Situada en la costa del término municipal de Ses Salines en Mallorca, su longitud es de $1,10 \mathrm{~km}$. En 1406 está documentada como isla del Moltí y de en Pujol (Gran Enciclopèdia de Mallorca, vol. XIII, p. 103).

57 Se estableció por cinco años con la condición que tenía que pagar 8 sueldos anuales (R. Rosselló, J. Bover, La fabricación de la sosa, pp. 28-29). Se trata de un islote de 1,02 km de longitud ubicado en la playa de Magaluf.

58 Pagó 5 sueldos por la licencia (R. Rosselló, J. Bover, Els vidriers de Mallorca, p. 503). Se trata de un grupo de dos islas, la mayor de aproximadamente $2 \mathrm{~km}$ de longitud.

59 M.M. Riera, Història de Cabrera, pp. 48, 55, 56, 60).

60 R. Rosselló, Notes històriques de Cabrera, pp. 8-9, 14-15; R. Rosselló, J. Bover, Els vidriers de Mallorca. Segles XIV-XVI, p. 413. 
importación de este género, sobre todo desde Valencia y Alicante ${ }^{61}$. Toda esta actividad comercial se constata a través de una significativa documentación notarial que los autores anteriores han recuperado y que aporta numerosos datos acerca de este colectivo de artesanos.

La fecha más antigua hasta ahora es del año 1448, momento en que Joan Amades reconocía deber a un mercader de origen valenciano el precio de unos 73 quintales y 80 libras de sosa sin defecto (3.093,2 kg). En 1474 era Pere Gil quien debía a Joana, mujer de Simó García, el importe de 25 quintales $(1.017,5 \mathrm{~kg})$. Este mismo personaje adeudaba $20(814 \mathrm{~kg})$ a Tomàs Forns. El año 1491 Bartomeu Ribers compraba a Joan Marcó del Reino de Valencia 100 quintales de sosa (4.070 kg). En 1498 Jeroni Àlvares adquirió unos 12 quintales $(488,4 \mathrm{~kg})$, sin que se especifique su procedencia ${ }^{62}$.

En cuanto al primer tercio del siglo XVI, parece que la dinámica es similar a la correspondiente a la segunda mitad del XV. Así, en 1505 Andreu Artal debía 15 quintales $(610,5 \mathrm{~kg})$ a un comerciante catalán ${ }^{63}$. Un seguro de la carga de una nave del año 1531 incluía barrilla de Alicante ${ }^{64}$. En 1545 Mateu Llorenç adquirió 12 cuarteras de barrilla originaria de Villena en el Reino de Valencia $^{65}$. Tres documentos notariales sitúan la compra de salicor utilizado en la elaboración de vidrio más fino, junto con la tradicional sosa. En 1479 Guerau Xatard reconocía deber a Arnau de España, cirujano, una cantidad por comprar 19,5 quintales de salicor $(793,65 \mathrm{~kg})$. Una noticia semejante es del año 1500, cuando Bartomeu Ribers debía a Joan Forcadell, mercader, 60 quintales de sosa $(2.442 \mathrm{~kg})$ y ocho de salicor $(325,6 \mathrm{~kg})^{66}$.

La entrada de sosa se limita al Levante peninsular. No se constata entre los siglos XIV y XVI la llegada desde el sur de Francia o de Italia, que serían otros centros productores mediterráneos significativos. Tampoco desde el norte de África, de donde sí se importará en una cronología mucho más avanzada. Además, no está claro que los importadores tuvieran que pagar un impuesto por el comercio de este material, como ocurría en el sur de Francia ${ }^{67}$ y en algunos territorios de la Corona de Aragón, en concreto en el Rosellón durante el XIII. No se puede determinar cuál era el precio de la sosa en fun-

61 R. Rosselló, J. Bover, Els vidriers de Mallorca, p. 495.

62 M.A. Capellà, El vidre a Mallorca, p. 909, doc. 17, pp. 917-918, doc. 27, 26, p. 925, doc. 34, p. 926, doc. 35; R. Rosselló, J. Bover, Els vidriers de Mallorca, pp. 495, 499, 502, 496.

63 R. Rosselló, J. Bover, Els vidriers de Mallorca, pp. 495, 496, 499, 502.

64 O. Vaquer, El comerç marítim, p. 136.

65 M.A. Capellà, El vidre a Mallorca, p. 959, doc. 65; R. Rosselló, J. Bover, Els vidriers de Mallorca. Segles XIV-XVI, p. 412.

${ }^{6}$ M. A. Capellà, El vidre a Mallorca, pp. 919, 928, doc. 29, 37; R. Rosselló, J. Bover, Els vidriers de Mallorca. Segles XIV-XVI, pp. 413, 415.

${ }_{67}$ H. Amouric, D. Foy, De la salicorne, p. 54. 
ción de la documentación conservada. La dificultad de establecer una tabla de costes se debe, entre otras razones, a que el producto podía ser de distinta clase, aspecto que introduce un factor de alza considerable en su cotización. Los cambios de valor detectados podrían indicar variaciones en la calidad de un mismo tipo de ceniza o bien deberse a diferentes cenizas confeccionadas a partir de hierbas diversas ${ }^{68}$. Las disputas por la calidad eran frecuentes. Así en 1521 Jacob Llop, procurador, y Joana, viuda de Antoni Sala, litigaban ante la curia de los Cónsules de Mar por 96 quintales de barrilla que la vidriera no estimaba satisfactoria para hacer vidrio. La cuestión no sabemos cómo se resolvió ya que el documento notarial quedó interrumpido ${ }^{69}$.

La cal es un elemento imprescindible en la composición del vidrio al estabilizar el objeto acabado, además de bajar la temperatura de fusión y evitar la opacidad del vidrio, pero se trata de un componente imperceptible en la documentación escrita de la época ${ }^{70}$. Los colorantes manejados en el período medieval eran ingredientes costosos y son difíciles de corroborar sus transacciones al ser cantidades pequeñas. Entre estas materias debemos destacar el manganeso, empleado principalmente para decolorar y para lograr el color violeta. El azul utilizado en las decoraciones se conseguía mezclando cobalto, preferentemente comercializado en la Europa central desde zona alemana ${ }^{71}$.

Finalmente, otro de los componentes usados en la transformación de la masa vítrea es el vidrio desechado. En el caso de Mallorca, disponemos de varias noticias que constatan este reciclaje. Una nave genovesa del siglo XIV transportaba entre otras mercancías algunos barrilia plena vitro coloris blavis que tenían como destino la isla ${ }^{72}$. En 1355, unas dudas presentadas sobre la recaudación de ayudas por el lugarteniente de Mallorca nos aportan nuevos indicadores $^{73}$. La nota hace referencia a la importación de vidrio roto, y a su exportación una vez se había refundido en diferentes objetos. El lugarteniente ordenaba que se cobrase por la entrada de este material y si no que pagase cuando se exportase una vez trabajado ${ }^{74}$. Se trata de una señal inequívoca de que se recogía material desde las otras islas para fusionarlo en los talleres mallorquines, aspecto que denota la escasa infraestructura productiva que habría en Menorca, lugar de procedencia de la embarcación. También es una prueba

H. Amouric, D. Foy, Notes sur la production, pp. 161, 170.

69 ARM, Not. D-88, ff. 64v-65r.

70 À travers le verre, p. 38.

71 B. Gratuze et al., The origine of cobalt blue, pp. 123-133.

72 D. Foy, Le verre médiéval, p. 39.

73 P. Cateura, La trentena, p. 101; R. Rosselló, Aportació a la història medieval de Menorca, pp. 137-140.

74 La tabla ofrecía dudas sobre la forma de aplicar el gravamen, que eran resueltas por el lugarteniente, pero no se indica la tasa concreta que se pagó (P. Cateura, La trentena, p. 100). 
de que estas actividades comerciales se gravaban con un impuesto, aunque podría ser un hecho puntual relacionado con la difícil coyuntura política y económica de aquellos años. Estos movimientos de mercancías a gran escala, señalan que cuando se rompía un objeto, sus restos eran guardados en contenedores específicos para su posterior reventa. Así, en 1481 Francesc de Milià, notario, tenía en el comedor de su casa un paner de vergueta ab ança dolents en què ha molt vidre trencat ${ }^{75}$. Esta circunstancia está ligada a la comercialización de nuevas piezas por los vendedores ambulantes o la compra en las tiendas urbanas, que añadían objetos extra a cambio de material deteriorado. Se trata de una actividad perfectamente contrastada en el resto de Europa.

\section{El COMBUSTIBLE}

La producción de vidrio supone un gasto elevado de madera, ya que para poder fusionar las materias primas y trabajarlas se requieren temperaturas muy altas, que obligan a mantener los hornos en funcionamiento, a menor rendimiento, incluso durante la noche, exigiendo un fuego constante y regular, factor que no se da en el gremio de la cerámica. Vista esta coyuntura, no es extraño que la primera noticia relativa al combustible sea la prohibición establecida por Jaume III en 1330 de fabricar vidrio y jabón por el excesivo consumo de leña, que ya hemos mencionado. Esta restricción perduró como mínimo hasta 1346, momento en que el Gobernador de Mallorca escribió al de Menorca para que impidiera que se cortase leña para hacer cenizas ${ }^{76}$. Marcel Durliat insinúa que esta limitación del consumo se debe a un auge de la labor de los vidrieros ligada a la promoción artística fomentada por la monarquía privativa $^{77}$. Cuando en 1347 se autorizó a Guillem Barceló a construir un horno de vidrio en Mallorca, en la Real disposición se le indicaba que sólo podía emplear unas cuatro somadas de leña al día $(163 \mathrm{~kg})^{78}$, que debían traerse desde fuera de la isla ${ }^{79}$.

La cuestión de la escasez de combustible ha sido un fenómeno que siempre ha condicionado la elaboración de vidrio, como demuestran los numerosos casos de manufacturas que se han eclipsado por la falta de este bien

75 Otro ejemplo lo tendríamos en el inventario de 1465 de Agustina Marsola (M. Barceló, G. Rosselló, Terrissa, pp. 226-231, 222-225), o la "sanalla xique plena de tessons tranquats" de un platero de 1517 (G. Llompart, Plata medieval, p. 75).

76 R. Rosselló, J. Bover, Els vidriers de Mallorca, p. 494.

77 M. Durliat, L'art en el Regne, p. 275.

78 Carga de un animal o equivalente a tres quintales.

79 E. de K. Aguiló, Industrias mallorquinas, pp. 318-320. 
a lo largo de la historia del vidrio ${ }^{80}$. Nos encontramos, pues, ante una actividad artesanal que puede arrasar la vegetación inmediata, siendo a la vez muy sensible y dependiente de su desaparición. La deforestación podría ocasionar conflictos con otros sectores productivos o incluso con los mismos vecinos, ya que la leña era casi la única fuente de energía disponible en la vivienda particular $^{81}$. Es por esta razón que son constantes las restricciones impuestas a los vidrieros en su consumo, con la finalidad de evitar una tala desmesurada, que debemos considerar mucho más letal al tratarse de una isla. En 1517 una cláusula contractual de un taller rural ejemplifica este asunto, al señalar que:

lo dit Pera Fortesa és tengut de dar los dos àsens e tanta lenya axí grossa com manuda, quanta auram menester per dit forn y més los darà palla per dits àsens e vol lo dit Pera Fortesa no li tallen ullastres, ni oliveres, ni alsines ${ }^{82}$.

El suministro era una de las máximas preocupaciones de los vidrieros urbanos, que se veían obligados a garantizar un servicio continuo, con un almacén cubierto en su infraestructura para contar con combustible en stock. Toda esta secuencia comportaba una red de trabajadores directamente vinculados a esta faceta de la actividad: leñadores, transportistas y atizadores encargados de mantener el fuego ${ }^{83}$. Estos almacenes constituían un peligro para las ciudades que, ante la acumulación de infraestructuras, podían prohibirlas en su interior, como sería el caso de Barcelona en 1323 y otras ciudades europeas $^{84}$. Una restricción similar a ésta fue la que se estableció en los aledaños del convento de Santa Clara de la Ciutat de Mallorca en 1307, cuando alrededor del conjunto monástico se habían construido casas en diversos solares. La priora de las clarisas prescribió una serie de condiciones que limitaban las actividades contaminantes, como eran las realizadas por tintoreros, alfareros y vidrieros ${ }^{85}$.

\footnotetext{
80 Incluso se puede dar la circunstancia que un taller rural pueda tener diferentes fases de ocupación correspondientes a cronologías diferentes debido a la recuperación del entorno natural (D. Foy, H. Amouric, Les artisanats, pp. 58-60).

${ }^{81}$ Un paradigma a nivel europeo se da en 1285 cuando el Consejo de la República de Venecia ante el peligro de deforestación impuso una serie de medidas restrictivas al consumo (D. Stiaffini, Il vetro nel medioevo, p. 37).

82 M.A. Capellà, Societats vidrieres, p. 59.

83 D. Foy, H. Amouric, Les artisanats, p. 58. Un ejemplo fue la sociedad establecida entre Esteve Maltès y dos vidrieros en 1549 , que especificaba la presencia de jornaleros y leñadores (ARM, Not. R-57, f. 22r-v).

84 J. Gudiol, Els vidres catalans, p. 32, D. Foy, L'accés aux matières, p. 120. Véase el análisis de la gestión en Barcelona: S. Cañellas, C. Domínguez, Intervenció de les institucions públiques en la producció de vidre, pp. 4-5.

85 J.C. Sastre, Espiritualitat $i$ vida quotidiana, p. 174
} 


\section{VIDRIEROS Y VÍNCULOS TERRITORIALES}

La diversidad de actividades y los procesos de elaboración de materiales de un taller dificultan la apreciación del número de individuos que se le pueden relacionar. En cuanto a Francia se ha calculado que una manufactura mediana requeriría aproximadamente unas diez personas ${ }^{86}$. En cambio, en Barcelona, el vidriero catalán Francesc Pujalt tenía en su mesa a 25 comensales vinculados a su horno ${ }^{87}$. Parece claro que podemos diferenciar dos grandes grupos de trabajadores: los artífices especializados y los que desarrollan labores polivalentes.

Los especializados corresponden al perfil de tres tipos de sujetos. En primer lugar, el maestro vidriero que ejerce su arte ayudado por su camarilla, y que en muchos casos sería propietario. En segundo, se pueden citar los obreros vidrieros que se contrataban por el período de un año, cobrando según las jornadas realizadas, la cantidad de material y la calidad, tanto en cuanto a su forma como su belleza. Por último, se situaría el aprendiz que tendría unas condiciones de trabajo menos favorables. Se adaptaría al esquema estándar propio de los gremios medievales, que es similar a la reglamentación de los vidrieros del año 1271 de la isla de Murano que especifica tres categorías: el patrón del horno, que no tiene porqué ser vidriero, el maestro vidriero y el obrero $^{88}$.

A los artífices especializados habría que sumar aquellos operarios que desempeñaban funciones polivalentes. Éstas irían desde la extracción y martilleado de la piedra, la elaboración o preparación de la sosa, el acondicionado del vidrio que había que reciclar, el picado de la frita y la provisión de combustible ${ }^{89}$. Se trata, como es obvio, de operaciones que requerían una enseñanza rudimentaria. En comparación con los anteriores, aluden a toda una serie de tareas más difíciles de constatar. Sin embargo, también se podrían encargar de estas labores tanto los aprendices como, de manera puntual, los vidrieros y, por supuesto, los esclavos.

Las denominaciones utilizadas en la documentación para indicar la profesión son diversas, amplias y, a veces, ambiguas ${ }^{90}$, ya que pueden hacer referencia a cuatro ocupaciones diferentes: soplador de vidrio, pintorvidriero, vendedor y propietario de taller. En este último ejemplo, podría

86 À travers le verre, p. 23.

87 D. Foy, Le verre médiéval, p. 59; C. Carrere, Barcelone centre économique, pp. 381-385.

88 A. Gasparetto, Il vetro di Murano, pp. 49-50.

89 Véase el contrato del horno del Pla d'en Llull de 1510: C. Domínguez, S. Cañellas, El forn de vidre del Pla d'en Llull, pp. 141-172.

90 D. Foy, Les verriers provençaux, p. 591. 
ejercer el oficio o tratarse de la figura de un empresario, que sólo aporta dinero y no su maestría. Además, hay que tener en cuenta que gran parte de los documentos notariales no están relacionados de forma directa con esta actividad artesana, sino que corresponden a otros aspectos de la vida diaria de un individuo. En ocasiones, sólo los conocemos por haber actuado de testigos en un acto o negocio jurídico, sin que se especifique nada más que la condición de vidriero.

Las dos tablas que presentamos se han elaborado analizando la numerosa documentación exhumada por diferentes historiadores y, en concreto, desde la relectura y ampliación de las tablas que ya hicieron Ramon Rosselló y Jaume Bover ${ }^{91}$. Hemos delimitado los años de actividad de los artesanos, el tipo de tarea que desarrollaban y, por último, su origen, que cuando no se ha indicado es porque está referenciado que son mallorquines. La inmigración en este colectivo es muy importante ya que nos remite a la presencia de artífices que han detectado una zona con poca competencia donde con facilidad podrán ejercer su oficio. Asimismo, es un factor determinante en la difusión de conocimientos, técnicas y estilos productivos. El tema de la migración en Mallorca durante la segunda mitad del XV ha sido analizado por Onofre Vaquer, mediante sendos trabajos que nos han proporcionado diversos datos ${ }^{92}$. En cambio, la falta de estudios concernientes al siglo XIV y la primera mitad del XV limita notablemente la información al respecto. El papel de este movimiento migratorio está aún por valorar. En cuanto al caso específico que nos afecta, es evidente que la llegada de vidrieros si la comparamos con otros profesionales de sectores similares, es poco significativa a nivel de la población existente. Otra de las dificultades radica en relacionar los escasos talleres con los menestrales conocidos. De hecho, los contratos de aprendizaje o de alquiler son limitados y, por tanto, muchos de los individuos no pueden ser ligados a una infraestructura concreta, por lo que desconocemos las operaciones que hacían.

El número de artesanos documentado en el siglo XIV es escaso. Hablamos, en términos generales, de trece vidrieros y dos aprendices. La mayoría de ellos son inmigrantes venidos desde diferentes lugares de Cataluña y Valencia, con la única excepción de dos sujetos que proceden de Francia.

91 R. Rosselló, J. Bover, Els vidriers de Mallorca, p. 506; R. Rosselló, J. Bover, Els vidriers de Mallorca. Segles XIV-XVI, p. 416.

92 O. Vaquer, Immigrants a Mallorca, pp. 125-140. También del mismo autor: Immigrants a Mallorca II, pp. 353-362. Debemos tener en cuenta que se trata de datos parciales, pero de los 577 inmigrantes citados de la segunda mitad del XV tan sólo uno era vidriero. 


\begin{tabular}{|l|l|l|l|}
\hline DOCUMENTADO & NOMBRE & CATEGORÍA & PROCEDENCIA \\
\hline 1327 & Roger, Guillem & vidriero & \\
\hline 1327 & Roger, Bernat & vidriero & \\
\hline 1327 & Mia, Tyhome de & vidriero & Picardía (Francia) \\
\hline 1328 & Humbert, Guillem & vidriero & \\
\hline 1328 & Corró, Pere & aprendiz & La Bisbal (Cataluña) \\
\hline 1329 & Nur, Guillermó & $\begin{array}{l}\text { vendedor- } \\
\text { aprendiz }\end{array}$ & Lers, Girona (Cataluña) \\
\hline 1347 & Barceló, Guillem & vidriero & Barcelona \\
\hline 1352 & Bartomeu, Miquel & vidriero & Barcelona \\
\hline 1363 & Maguera, Joan de & vidriero & Renys (Francia) \\
\hline $1369-1415(\dagger)$ & Guerau, Guillem & vidriero & \\
\hline $1387-1402$ & Rotlan, Francesc & vidriero & \\
\hline 1387 & Sala, Antoni (I) & vidriero & Barcelona \\
\hline 1390 & Bertran, Francesc & vidriero & \\
\hline $1392-1413$ & Coloma, Nicolau & vidriero & Barcelona \\
\hline 1394 & Martí, Julià & vidriero & \\
\hline
\end{tabular}

Entre 1402 y 1450 son veinte vidrieros y dos aprendices los conocidos a través de las fuentes. En la mayor parte de los casos se trata de ciudadanos de Mallorca y sólo se detectan ocho inmigrantes de la misma procedencia.

\begin{tabular}{|l|l|l|l|}
\hline DOCUMENTADO & NOMBRE & CATEGORÍA & PROCEDENCIA \\
\hline 1402 & Salvatge, Joan & vidriero & \\
\hline $1402-1403$ & Sembreses, Galceran & vidriero & Vic (Cataluña) \\
\hline 1403 & Guasc, Pere & vidriero & Valencia \\
\hline 1404 & Morales, Alfonso de & aprendiz & Arisa (Aragón) \\
\hline $1407-1418$ & Lloreda, Joan & vidriero & \\
\hline $1408-1443(\dagger)$ & Sala, Pere (I) & vidriero & \\
\hline $1410-1438$ & Coloma, Martí & vidriero & \\
\hline 1415 & Garau, Guillem & vidriero & \\
\hline 1426 & Gensana, Guillem & vidriero & $\begin{array}{l}\text { La Reial de la Conca de } \\
\text { Barberà (Cataluña) }\end{array}$ \\
\hline $1426-1476$ & Ferran, Guillem & vidriero & \\
\hline 1429 & Serra, Joan & vidriero & \\
\hline
\end{tabular}




\begin{tabular}{|c|c|c|c|}
\hline 1439 & Serra, Guillem & vidriero & \\
\hline 1440 & Sala, Pere (II) & vidriero & \\
\hline 1440-1446 & Rafal, Bartomeu & vidriero & \\
\hline $1441-1460$ & Sala, Antoni (II) & vidriero & \\
\hline 1444 & Adam, Pere & vidriero & \\
\hline 1445 & Soler, Miquel & vidriero & Piera (Cataluña) \\
\hline 1445 & Pons, Guillem & aprendiz & \\
\hline $1445-1448$ & D'Amades, Joan & vidriero & Xiprana \\
\hline 1446 & Alguaire, Miquel & vidriero & \\
\hline 1448 & Sala, Pau & vidriero & Barcelona \\
\hline 1448 & Gassó, Francesc & vidriero & Valencia \\
\hline 1451-1469 & Vallets, Joan & $\begin{array}{l}\text { vendedor- } \\
\text { vidriero }\end{array}$ & \\
\hline $1456-1474$ & Gil, Pere & vidriero & Castelló (Cataluña) \\
\hline 1459 & Xerar, Antoni & vidriero & \\
\hline 1459 & Solà, Antoni & vidriero & \\
\hline $1459-1508(\dagger)$ & Xatard, Antoni & vidriero & \\
\hline $1460-1492(\dagger)$ & Sala, Antoni (III) & vidriero & \\
\hline 1461 & Coloma, Joan & vidriero & \\
\hline 1474 & $\begin{array}{l}\text { Fortuny de Ruesca, } \\
\text { Jordi Joan }\end{array}$ & propietario & \\
\hline 1478 & Garau, en & vidriero & \\
\hline $1465-1478$ & Arcís, Joan & vidriero & \\
\hline 1479 & Xatard, Guerau & vidriero & \\
\hline 1482-1485 & Martí, Arcís & vidriero & \\
\hline $1482-1490$ & Xatard, Pere & vidriero & \\
\hline 1482 & Xatard, Francesc & vidriero & \\
\hline 1488 & Ferrando, Francesc & aprendiz & Jaén \\
\hline $1476-1482$ & Caselles, Joan & vidriero & \\
\hline 1492 & Piçà, Pere & vidriero & \\
\hline 1492 & Xatard, Ramon & vidriero & \\
\hline 1492 & Serra, Joan & vidriero & \\
\hline 1494-1496 & Jordà, Jordi & vidriero & \\
\hline
\end{tabular}


En relación a la segunda mitad del siglo, se documentan aproximadamente diecisiete vidrieros y dos aprendices. La mayoría de ellos ya son originarios de la Ciutat de Mallorca, lo que deja entrever que la inmigración se ha reducido de manera notable y que se han consolidado determinadas familias en el control de la producción. Estas tablas muestran una información más rica que la que hasta ahora se había manejado, extraída prioritariamente de varias tallas. Así, por ejemplo la de $1478^{93}$ nos permite fijar la residencia de algunos de estos profesionales: dos en la parroquia de Santa Eulalia y tres en la de San Miguel. En la primera parroquia se sitúa el vidriero Joan Arcís, en la manzana del Temple. En cuanto a San Miguel se remarca el protagonismo de la Ylla d'en Sala ${ }^{94}$, en la que vivían Antoni Xatart y Antoni Sala. En el bloque inmediatamente anterior residía Garau. La talla de 1483 presenta un número similar de personajes dedicados a la vidriería: uno, en Santa Eulalia, y tres, en la parroquia de San Miguel Aunque nos pueda parecer reducida la cuantía de vidrieros registrados en el documento, podemos comprobar cómo la cantidad de alfareros también es relativamente exigua (cuatro en 1478, cinco en 1483). El grupo de los pintores no sería mucho más significativo, así en 1478 se computan cuatro y cinco en 1483. Tan sólo los plateros aparecen en una proporción muy superior (catorce en 1478 y diecinueve en 1483) ${ }^{95}$.

El artesanado del vidrio, como ocurre con otros oficios, se encuentra en manos o bajo el control de algunas familias a lo largo de varias generaciones ${ }^{96}$. Se puede hablar de una cierta endogamia y de unas relaciones de parentesco muy estrechas en el ejercicio de esta ocupación, ya que diferentes miembros de un mismo linaje comparten actividad. Al fin y al cabo, tres son las causas determinantes que conducen a esta tesitura: el escaso número de artífices, la demanda de productos y los pocos talleres existentes en la Ciutat de Mallorca y, por extensión, en las islas. Este factor clánico tan acentuado se retroalimenta con la inexistencia de un gremio que regulase al colectivo.

Es en este contexto que debemos situar los llamados en la época "señor de vidriería" o "señor del vidrio". El señor es el personaje que aporta toda la infraestructura, es aquel que disfruta de los medios y del capital, y que se asocia en algunos casos a técnicos con conocimientos especializa-

93 M. Barceló, Ciutat de Mallorca, pp. 199-200.

94 A. Canyelles, Tall per una armada, p. 17.

95 M. Barceló, Ciutat de Mallorca, pp. 165-169, 170-171, 251.

96 Lo mismo pasa en la Francia mediterránea, en especial a lo largo del siglo XV (D. Foy, Les verriers provençaux, p. 596). 
$\operatorname{dos}^{97}$. Este hecho no quiere decir que excluya su intervención como maestro vidriero, todo lo contrario. Se trata de un modelo de organización del trabajo, que presenta numerosas similitudes con los empleados en otras profesiones afines en el final de la Edad Media, como son las de los alfareros o los tintoreros ${ }^{98}$.

La primera familia que ejercerá gran influencia, manteniendo la producción casi como si se tratara de un monopolio, es la de los Coloma. Su actividad con un horno que ya hemos localizado cerca del Pes de sa palla se concentra entre los años 1392 y $1436^{99}$. Probablemente, eran originarios de Barcelona, como se extrae de la aceptación de la herencia del hermano de Nicolau Coloma ${ }^{100}$, Joan, vidriero establecido en la ciudad catalana ${ }^{101}$.

El paradigma de organización familiar es la dinastía de los Sala, que mantuvieron abierto su taller entre 1408 y 1527, controlando la producción del vidrio durante la segunda mitad del siglo XV y el primer tercio del XVI en la Ciutat de Mallorca ${ }^{102}$. El primero de esta saga es Antoni Sala (I), hijo del maestro Francesc de Barcelona, que se contrató con Francesc Rotlan para trabajar juntos en $1388^{103}$. El siguiente miembro del que tenemos una actividad mucho más contrastada es Pere Sala (I). Artesanos con este linaje regentaron diferentes hornos en Vallromanes (Cataluña) ${ }^{104}$. En este sentido, como afirmaron Ramon Rosselló y Jaume Bover, se dan varios hombres de esta familia con el mismo nombre propio, circunstancia que dificulta la delimitación de las respectivas actividades. Hoy por hoy, la búsqueda sistemática en los protocolos notariales nos ha permitido delimitar los años de vida de los principales protagonistas de este grupo: Pere I (1408-1443 †), Antoni II (1441-1460 †) y Antoni III (1460-1509 †).

Entre los diversos documentos localizados deben destacarse el testamento d'Antoni Sala de 1460 y el de su viuda de 1462, que nos han facilitado

${ }_{97}$ M. Bernat, J. Serra, El forn de vidre, p. 105. El caso de Jordi Joan Fortuny de Ruesca en 1474 no nos permite identificarlo como señor de vidriería, ya que sólo la alquiló como vivienda, sin que se constate la utilización del horno de vidrio de su corral.

98 M. Bernat, La manufactura del sabó, pp. 238-241; M. Barceló, G. Rosselló, Terrissa, p. 202. Las circunstancias de los alfareros son idénticas.

99 R. Rosselló, J. Bover, Els vidriers de Mallorca, pp. 497-498.

100 En 1403, Nicolau, nombró procurador a su hijo Martí Coloma (R. Rosselló, J. Bover, Els vidriers de Mallorca, p. 497; ARM, Not. M-94, f. 64r-v).

101 Activo en esta ciudad a finales del siglo XIV: M.C. Riu, Onomástica y localización de algunos ceramistas y vidrieros, p. 1052.

102 R. Rosselló, J. Bover, Els vidriers de Mallorca, pp. 502-505.

103 ACM, 14717, s.f. Véase nota 4.

104 Si existía alguna relación familiar directa en estos momentos no se puede corroborar. Las noticias de la actividad de los Sala en esta localidad catalana van desde aproximadamente 1417 hasta 1487 (J. Gudiol, Els vidres catalans, p. 39; A.W. Frothingham, Spanish Glass, p. 24). 
el análisis de aspectos profesionales, sociales, consanguíneos y económicos. En relación al lugar de enterramiento, eligieron sepultura en el convento de San Francisco, aunque eran parroquianos de San Miguel. Además, tanto en el caso de Antoni, del año 1460, como en su esposa, de dos años después, daban dinero a la mencionada parroquia entre otros templos ${ }^{105}$. Sus hijos, Antoni, Joan, Pere y Gaspar, probablemente también tuvieron un papel en el sector familiar, pero sólo nos consta la continuidad a través del primogénito.

Estos dos testamentos además nos permiten fijar los estrechos nexos de parentela que se establecieron entre diferentes estirpes vidrieras, en concreto con los Xatard. Antoni Xatard se había casado con una hija del matrimonio anterior, circunstancia que explica algunos factores vinculados con esta saga. De estos lazos, se puede deducir que debían trabajar con los Sala ${ }^{106}$. De hecho, el mismo individuo vivía en la illa d'en Sala, en la parroquia de San Miguel. Un documento de 1482 nos plantea la duda de si los Xatard regentaban un taller en propiedad. Dicho año, Pere Xatard, alquiló algunas de las bocas del horno a otros artesanos. Los Xatard aparecen en Mallorca entre los años 1459 y 1511. La estirpe era originaria del Rosellón ${ }^{107}$, aunque no podemos concretar esta relación familiar por la falta de una referencia explícita. Vidrieros con este mismo linaje tenían factorías en Palau del Vidre, que fueron administradas durante varias generaciones, con una gestión que se sitúa desde la primera mitad del siglo XIV hasta principios del XVI. Es evidente que los lazos de parentesco son difíciles de precisar, así como también indicar cuántos hornos mantenían activos en esa localidad ${ }^{108}$.

Entre el personal vinculado a un taller podía haber mano de obra esclava, que se encargaría de diferentes operaciones, en principio, no especializadas ${ }^{109}$. Por lo tanto, es normal que hayan salido a la luz muchos documentos de compra-venta relacionados con las familias vidrieras más reconocidas. Los hombres podían intervenir en las diferentes tareas tanto cualificadas como no, circunstancia común con otras actividades menestrales, como las de los alfareros o los tintoreros ${ }^{110}$. En nuestro caso, en ninguno de los contratos de

105 Los dos legaron dinero a la Catedral, Santa Eulalia, al convento del Carmen y al convento de Nostra Dona dels Àngels o de Jesús (ARM, Not. P-363, ff. 59r-60r, ARM, Not. P-363, ff. 83r-84r). Para un análisis de este tipo de documentación véase: M.C. Riu, Ceramistas y vidrieros, pp. 254-260.

106 Antoni Sala se comprometía a que se pagase después de su muerte los 100 florines de la dote de su hija.

107 R. Rosselló, J. Bover, Els vidriers de Mallorca, pp. 505-506; J. Gudiol, Els vidres catalans, p. 32; M. Camiade, D. Fontaine, Verreries et verriers catalans, pp. 16-18.

108 D. Foy, Le verre médiéval, pp. 76-77.

109 O. Vaquer, L'esclavitud a Mallorca, p. 55

110 M. Barceló, G. Rosselló, Terrissa, p. 201. 
venta se especifica que conocieran el oficio, un aspecto que se reafirma cuando la cesión no se produce entre los miembros del mismo colectivo. Las mujeres solían encargarse del servicio doméstico de la casa. Así, Miquel Alguaire en 1446 tenía suficiente poder adquisitivo como para tener una criada, que antes había sido esclava de Nicolau Gomila. Además, tenía en propiedad a otro cautivo ruso ${ }^{111}$. Es el único ejemplo en que un artesano que no podemos calificar como señor de vidriería, dispone de recursos para ello.

La familia Sala tuvo, dado su control de la producción y el consecuente potencial económico, una gran actividad en la compra-venta de cautivos. En el año 1440, Pere Sala (I), vendió uno a Joan Mas. Los testigos fueron un hijo suyo y Bartomeu Rafal, ambos vidrieros ${ }^{112}$. Su cónyuge, en su testamento de 1453, prometió la libertad a Catalina, de doce años, y a Joan, de nueve años, hijos de Juliana. También a Gabriel, de tres años, vástago de Catalina, esclava rusa, a la que se le concedería la manumisión una vez fallecida la testadora ${ }^{113}$. Ese año ya había liberado a otra ${ }^{114}$. Se trataría de personas relacionadas con el servicio doméstico, cuya presencia refleja la pujanza de la estirpe. Más adelante Antoni Sala (III), entre los años 1488 y 1490, vendió dos negros de unos veinte años. El primero, a Pere Companyó por 30 libras y el segundo, a Nicolau Muntaner, mercader, por otras 30.

La comercialización del producto acabado se efectuaba por diversas vías, algunas de ellas difíciles de corroborar. Entre las más comunes se pueden enumerar la venta directa en el obrador, en una tienda, que en gran parte de los casos podría ser la casa u horno y, finalmente, la ambulante ${ }^{115}$. Las transacciones se podían hacer a través de los miembros de una misma familia o bien mediante la intervención de intermediarios. No nos consta que hubiera algún tipo de impuesto que gravase este negocio ${ }^{116}$.

La documentación no es clara, como ya se ha indicado, dado que en ocasiones no permite distinguir entre los fabricantes y los vendedores, a quienes incluso se les denomina vidrieros. Estos últimos se dedicaban a la reventa, tanto de objetos adquiridos en los talleres locales como de importados, efectuando después una redistribución por la isla. Este sería el caso de Joan Vallets

111 R. Rosselló, J. Bover, Els vidriers de Mallorca, p. 410.

112 ARM, Not. M-227, f. 223v. Este mismo año vendió otro por 30 libras (ARM, Not. M-227,f. 140v).

113 O. Vaquer, L'esclavitud a Mallorca, p. 49, 117.

114 ARM, Not. F-123/4790, f. 8v.

115 M.C. Riu, El treball artesà a Barcelona, p. 556.

116 En Barcelona el Consell de Cent obligaba al pago de un impuesto por los productos fabricados y vendidos por olleros, alfareros y vidrieros (M. C. Riu, El treball artesà a Barcelona, p. 553), mientras que en las ciudades de la Francia mediterránea se gravaba cuando entraba este producto (D. Foy, Le verre médiéval, pp. 371-372). 
a quien en algunos justificantes se cita como vidriero y en otros como vendedor. Se documentan varios pagos realizados entre 1451 y 1459 por diversas cantidades de vidrio llegadas desde procedencias varias ${ }^{117}$. Así, sabemos que en 1453 Vallets, junto con su mujer y el tendero Pere Ilani, debían 73 libras y 1 sueldo por 15 botas llenas de vajilla enviada desde Valencia.

La cantidad de vendedores constatados es bastante menor a la de fabricantes. Hemos optado por no incluir en el listado cronológico los diferentes hornos que también hacían venta directa. Sólo lo hemos hecho cuando expresamente se conoce que algún componente de la familia se dedicaba a esta tarea de manera específica. El número de comerciantes correspondiente al siglo XIV es notablemente inferior al de la centuria siguiente, en paralelo con lo que sería la expansión de la manufactura y de su consumo entre la sociedad. Así, se conocen dos comerciantes en el XIV y siete en el XV.

\begin{tabular}{|l|l|l|l|}
\hline DOCUMENTADO & NOMBRE & & PROCEDENCIA \\
\hline 1328 & Gallard, Miquel & vendedor & Magalló (Cataluña) \\
\hline 1329 & Dalmau, Guillermó & vendedor & Vilafranca (Cataluña) \\
\hline 1349 & Pont, Joan & ¿vendedor? & \\
\hline $1398-1402$ & $\begin{array}{l}\text { Estefana, mujer de } \\
\text { Nicolau Coloma }\end{array}$ & vendedora & \\
\hline 1405 & Clara, Na & vendedora & \\
\hline 1407 & Maura, Antoni & vendedor & \\
\hline 1445 & Benejam, Llorenç & vendedor & \\
\hline 1446 & Salt, Pere & vendedor & \\
\hline $1451-1469$ & Vallets, Joan & $\begin{array}{l}\text { vendedor- } \\
\text { vidriero }\end{array}$ & \\
\hline 1466 & Bonanat, Hug & vendedor & \\
\hline 1466 & Bonanat, Joan & vendedor & \\
\hline
\end{tabular}

En la tabla anterior no figuran tres judíos vendedores de hierro y vidrio, declarados insolventes en $1350^{118}$. Según Margalida Bernat se trataría de comerciantes especializados en la venta de materiales para la construcción, si bien se podría argumentar, fundamentándose en el simple hecho de no pagar, que su actividad estaría relacionada con la compra de vidrio roto para su posterior reciclaje.

117 R. Rosselló, J. Bover, Els vidriers de Mallorca, p. 505.

118 "Ít(em), an Moxí Matatí, qi ven fero e vidra" (J. Miralles, Corpus d'antropònims, p. 319, 330, M. Bernat, El call, pp. 59, 76). 
Los hornos rurales necesitaban vendedores que transportasen su producto a la ciudad o bien a las villas. Así, por ejemplo, en 1328, Miquel Gallart, mayor de 18 años, se colocó con el maestro Humbert para vender objetos por las villas, a cambio de mantenerlo vestido y alimentado ${ }^{119}$. La distribución en la ciudad se realizaba sobre todo en los propios centros productores. El taller de los Coloma vendía directamente en su tienda del Pes de sa palla. De esta actividad se encargaba su esposa, Estefana ${ }^{120}$. Así, sabemos que en 1402 Joan Salvatge le debía cierta cantidad de dinero por vidrio obrado ${ }^{121}$. También se efectuaron ventas a otros comerciantes como la de 1407 a Antoni Maura, que debía cuatro libras y 17 sueldos $^{122}$. Lo mismo se puede decir del horno de la familia Sala. Además, los vidrieros disfrutaban de toda una serie de clientes, que redistribuían sus producciones. En 1428 Pere Sala exportaba una tinaja llena de piezas en la coca de Bernat Charo, genovés, en dirección a Bugía. El pedido era del marinero Miquel Masnou para revender en el norte de África, por precio de 77 sueldos $^{123}$. Se trata del único caso en que se documenta una exportación de materiales vítreos locales hacia otros territorios. Parece claro que los talleres mallorquines suministraron esta materia como mínimo a Menorca y Eivissa ${ }^{124}$.

Un lugar importante en la distribución en la Ciutat de Mallorca, aparte de los hornos, era la Calle de la Vidriería ${ }^{125}$, situada detrás de la iglesia de Santa Eulalia, la parroquia más extensa de la urbe, que aglutinaba a los principales edificios del poder político-administrativo, económico y religioso, junto a la herrería, la alfarería y otros oficios menestrales ${ }^{126}$. En contraste con algunas de estas últimas zonas, se puede decir que la Vidriería se encontraba más cerca del centro neurálgico de la ciudad ${ }^{127}$. Una referencia corresponde al pago de un censal por parte de un mercader en el año 1496 per les cassas poceeix en la plassa dal vidra al costat den Johan Rul, apotacari ${ }^{128}$. Calle o plaza que se encontraba en la época entre la del Cuiram y la de la Carnicería de arriba, espacios cercanos a Santa Eulalia ${ }^{129}$. Los vidrieros tenían instaladas mesas o puestos en esta zona para despachar sus productos. La tienda me-

119 R. Rosselló, J. Bover, Els vidriers de Mallorca, p. 500.

120 Ibidem, p. 497.

121 Ibidem, p. 504.

122 Ibidem, p. 497.

123 Ibidem, pp. 502-503.

124 ARM, Not. P-365, f. 121v.

125 D. Zaforteza, La Ciudad de Mallorca, vol. V, p. 347.

126 M. Barceló, G. Rosselló, La ciudad de Mallorca, pp. 155-157.

127 R. Rosselló, J. Bover, Els vidriers de Mallorca, p. 413.

128 ARM, Not. P-490, f. 52v

129 M. Barceló, G. Rosselló, La ciudad de Mallorca, p. 290. 
dieval se abría a la calle con los objetos expuestos a la vista, una imagen que no estaría demasiado alejada de las de cerámica y de otros géneros sin deter$\operatorname{minar}^{130}$, que se pueden ver en la visión idealizada de la Ciutat de Mallorca perteneciente al retablo de San Jorge de Pere Nisart, pintado hacia el $1480^{131}$. La actividad parece que se podría remontar a principios de la centuria, ya que se documentan entre 1411 y 1419 diferentes compras hechas al vidriero que estaba próximo a la Peixateria ${ }^{132}$, para la sacristía de la Catedral ${ }^{133}$. Un aspecto específico de esta vía es que en ella no se ubicaban talleres, sino que la Vidriería se caracterizaba exclusivamente por la reventa de materiales importados o venta de obra local. En Barcelona, hacia mediados del siglo XIV, ya existía la calle del Vidre ${ }^{134}$, circunstancia que no hemos podido constatar en la Ciutat de Mallorca. En el sur de Francia, poblaciones como Aviñón, Arlés o Montpellier tenían estas vías desde finales del XIII, vinculadas al comercio, pero también en algunos casos a la fabricación ${ }^{135}$.

En las ciudades asimismo había la posibilidad de la venta ambulante, que se hacía puerta a puerta. La figura de este revendedor se concreta en la peculiar imagen de un individuo con las piezas cuidadosamente depositadas en cestas de palma, como Joan Pont que en 1349 tenía dos banastas abtas ad portandum vitreum ${ }^{136}$, o bien enhastadas en una rama vegetal seca ${ }^{137}$. A la vez que realizaba la venta de objetos nuevos podía recoger material roto para reciclarlo en las factorías. No sabemos si es el caso de Mallorca, pero esta distribución podía ser una competencia directa a los obradores y tiendas. En Barcelona, se limitó a mediados del XV, ya que perjudicaba notablemente a estos lugares fijos ${ }^{138}$. Como norma general, el vendedor ambulante no trabajaba por su cuenta, sino que era asalariado de un revendedor o de un fabricante ${ }^{139}$.

130 M. Barceló, G. Rosselló, Terrissa, p. 207. En Italia se conservan algunos dibujos de tiendas de venda de vidrio del siglo XVI (D. Stiaffini, Il vetro nel medioevo, pp. 135-136, fig. 137).

131 G. Llompart, País, paisatge i paisanatge, pp. 58-89.

132 La identificación topográfica se hace en base a la existencia de una única pescadería situada próxima a la iglesia parroquial de Santa Eulalia (M. Barceló, G. Rosselló, La ciudad de Mallorca, p. 292). No hemos podido saber quien tenía a su cargo esta tienda a inicios del siglo, nos consta que el vidriero hacía donación al convento de San Domingo: "Habuimus del vedrier de la Pesqueteria quos dimisit in suo ultimo testamento, X s." (J. Rosselló, El convento de Santo Domingo, p. 127).

133 ACM, 1411, f. 84v; ACM, 1419, f. 50v.

134 J. Gudiol, Els vidres catalans, p. 32.

135 D. Foy, Le verre médiéval, pp. 374-375.

136 ARM, Not. A-29, f. 136r-v

137 M.C. Riu, Vida cotidiana de los ceramistas y vidrieros, p. 343. Las representaciones iconográficas de vendedores ambulantes son frecuentes tanto en Francia como en Italia (À travers le verre, pp. 364-365, fig. 403, 404; D. Stiaffini, Il vetro nel medioevo, pp. 136-137).

138 J. Gudiol, Els vidres catalans, p. 38.

139 À travers le verre, p. 364. 
A diferencia de lo que pasa dentro de la capital, el vidrio se vendía en las villas mallorquinas tanto en establecimientos no especializados como por vendedores itinerantes. Gabriel Llompart ha trazado con precisión el perfil de este redistribuidor que proporcionaba al campesino artículos comerciales e industriales de primera o segunda necesidad ${ }^{140}$. Como ejemplo paradigmático se puede citar la tienda que el sastre Pere de Viana tenía en la villa de Artà en 1467. Los objetos ofrecidos procedían de diversos sectores productivos: tejidos y otras piezas de indumentaria, mercería, metales, piel, material de escritorio, útiles de iluminación, farmacia, especies... Y entre todos estos productos, también las piezas de vidrio, tanto las correspondientes al servicio de mesa, como otras más suntuarias como son los espejos y la joyería. Otro caso de esta función en el campo era Llorenç Benejam, que en 1445 tenía una deuda por un pedido de vidrio y un asno a Andreua, viuda de Pere Sala (I). Aunque se le ha considerado un tendero de la villa de Sineu, lo más probable es que se tratara de un revendedor ambulante especializado en esta materia.

\section{LA ORGANIZACIÓN LABORAL}

En la Ciutat de Mallorca, a diferencia de Barcelona, no había unas ordenanzas que regulasen el oficio ${ }^{141}$. La circunstancia de la no asociación es un factor que no ha pasado desapercibido por los historiadores que han afrontado el estudio de esta actividad en la isla ${ }^{142}$. Uno de los aspectos más sorprendentes es que, a pesar del reducido número de artesanos, no se asociasen con los esparteros como sucedió en Barcelona ${ }^{143}$. De hecho, queremos hacer notar que el gremio de esparteros en Mallorca se fundó en $1472^{144}$. Si bien es importante también tener en cuenta que otras ciudades del arco mediterráneo, como por ejemplo Valencia, no tuvieron ningún tipo de organización que agrupase a los vidrieros ${ }^{145}$. Como contrapartida, debemos tener en cuenta que no se trata, ni mucho menos, del único colectivo en Mallorca que no contó con cofradía ${ }^{146}$. A

140 G. Llompart, Botiguers, p. 179.

141 J. Gudiol, Els vidres catalans, pp. 37-38, 136-139; L. Planell, Vidrio, pp. 99-105, 133-142.

142 M. Bernat, J. Serra, El forn de vidre, p. 108; M.C. Giménez, El vidrio soplado, p. 27.

143 En Barcelona los vidrieros tenían más prestigio social y se unieron con los esparteros debido a que eran pocos artesanos, ya que mantenían una estrecha relación al proteger con esparto muchas de las piezas de vidrio (M.C. Riu, El treball artesà a Barcelona, p. 555).

144 Tenían como patrón a San Luis, obispo de Tolosa; la capilla del gremio se situaba en la iglesia de San Francisco (B. Quetglas, Los gremios de Mallorca, pp. 120-121).

145 F. Almela, La antigua industria del vidrio en Valencia.

146 Jaboneros y alfareros son otros oficios sin gremio en la Mallorca bajomedieval. 
nuestro entender, la causa determinante que explica la inexistencia de corporación es la propiedad del taller y el escaso número existente, desde donde las familias propietarias ejercieron un férreo control que impidió el crecimiento de la manufactura, para mantener el arte del vidrio bajo el monopolio de unas pocas castas.

Ante la falta de unos capítulos del oficio, no nos queda más remedio que esbozar a partir de las exiguas referencias documentales cuáles eran las normativas consuetudinarias que afectaban al vidriero. La información que proporcionan los protocolos notariales permite ver cómo se establecen los nexos profesionales y cuáles son los diferentes sistemas de trabajo usados entre los diversos protagonistas en esta secuencia cronológica. Seguramente la situación no se encuentra demasiado alejada de la de otras ocupaciones no reglamentadas.

La ordenación del obrador responde a la típica medieval, caracterizada por el ejercicio del arte de forma colectiva, en la que los hornos están concebidos para la labor simultánea de varios artesanos. Ahora bien, en cuanto al vidrio, ésta no es una particularidad exclusiva del período medieval, ya que la propia naturaleza de la materia y la técnica implica casi siempre la colaboración de uno o dos ayudantes, que faciliten la tarea del artífice.

La documentación es generosa en cuanto a la cantidad de contratos localizados, permitiéndonos identificar distintos vínculos a través de tres tipos de acuerdo: los de aprendizaje, los de maestros o/y el alquiler de una porción de la infraestructura y las sociedades. Las incógnitas quedan pendientes en relación a cuál era el tiempo exacto de aprendizaje, y cómo y cuándo se realizaba la promoción a maestría. Por otra parte, tampoco se especifica de qué manera se regulaba la llegada de vidrieros desde otros territorios $^{147}$.

Los contratos de afianzamiento o aprendizaje son pocos, lo que puede deberse al factor ya remarcado de la escasez de talleres. Asimismo, la transmisión del oficio en el núcleo familiar, de padres a hijos, sería otra característica de la que prácticamente no tenemos documentos, aunque la continuidad es evidente $^{148}$. Como norma general, todos estos contratos especifican la duración del tiempo de amaestramiento, que podía variar entre uno y cuatro años, así como

147 En Barcelona se realizaba una prueba delante de maestros elegidos por la cofradía. Los extranjeros tenían que realizar el mismo proceso (M.C. Riu, El treball artesà a Barcelona, p. 553).

148 Coincide con lo que pasaba en la Francia mediterránea, tanto en Provenza como en el Languedoc (D. Foy, Le verre médiéval, p. 60). En los capítulos de otros oficios se dispensaba a los hijos de maestros la obligación de pasar el aprendizaje y de realizar el examen de acceso a la maestría. Así, se les facultaba a heredar el taller y ejercer como maestros (A. Santamaría, La formación, p. 661). 
las condiciones de vida de estos aprendices, que residían en la casa-taller del contratista, comiendo con el maestro-tutor, obligándole a servirle y obedecerle en los negocios lícitos que realizara. De hecho, la manutención y el vestido eran fundamentales en el compromiso ${ }^{149}$. Por otra parte, el maestro debía enseñar el oficio y cuidar al afianzado si enfermaba. Otro de los aspectos que aclaran es la edad, en algunos casos, su origen social, la situación laboral del padre y su procedencia. Como es habitual, se estipula el precio por la labor y el intervalo de los pagos ${ }^{150}$.

Los contratos de aprendizaje más antiguos son de principios del siglo XIV. En 1328 Pere Corró de Sa Bisbal, mayor de veinte años, pactó ser aprendiz de Guillem Humbert ${ }^{151}$. En 1404 el aragonés Alfonso de Morales se colocó con Nicolau Coloma para instruirse en el oficio, recibiendo ropa y alimentos a lo largo del período ${ }^{152}$. En 1445 Guillem Pons se colocó con Bartomeu Rafal, vidriero de Mallorca, por tres años para aprender y servirle, como era costumbre. El maestro se comprometía a proporcionarle indumentaria y a mantenerle, dándole diez florines de oro por cada año ${ }^{153}$. No nos consta que Rafal fuera amo de un horno, por lo tanto debían trabajar en la instalación de otro maestro o propietario y contrataba a un practicante para enseñarle el arte y ayudarle en su actividad.

Los arrendamientos se efectuaban entre el patrón de un taller y un vidriero. Un primer ejemplo es el que en 1403 se establece entre Nicolau Coloma y Pere Guasc de Valencia. En la mayoría de ocasiones, el arrendador se responsabilizaba de tener una boca del horno y de servir por un año al dueño, cobrando ocho libras anuales ${ }^{154}$. Otro caso se dio en 1482, cuando Pere Xatard cedió dos obrajes a Arcís Martí y Francesc Xatard, probablemente un familiar suyo. Desconocemos de qué infraestructura se trata, pero todo parece indicar que, por lo que ya hemos comentado, es la de los Sala. La duración del acuerdo es diferente para los dos: mientras que para el primero

149 La mayoría de corporaciones requerían un aprendizaje de cuatro años, aunque en ocasiones oscilaba desde un año hasta seis (A. Santamaría, La formación, pp. 655-656; O. Vaquer, El contrato de trabajo, p. 645).

150 Las ordenaciones del gremio de Barcelona fijaban que un aprendiz no podía contratarse con otro maestro si no se había cumplido el período fijado o disponía del consentimiento del primero (J. Gudiol, Els vidres catalans, p. 139). Algunos ejemplos demuestran que en Francia los aprendices pagaban por su formación (D. Foy, Les verriers provençaux, p. 595).

151 R. Rosselló, J. Bover, Els vidriers de Mallorca, p. 498, 500. En 1329 ocupó a dos aprendices más (ACM, 14556, ff. 105r, 167r).

152 R. Rosselló, J. Bover, Els vidriers de Mallorca, p. 497.

153 ARM, Not. M-167, f. 77r-v.

154 M.A. Capellà, El vidre a Mallorca, p. 897, doc. 7; R. Rosselló, J. Bover, Els vidriers de Mallorca, p. 497. 
se realiza por tiempo de un año, con respecto al segundo sería de dos ${ }^{155}$. Esta circunstancia puede deberse básicamente a las relaciones de parentesco, el conocimiento de la técnica o también a una salud precaria del primero ${ }^{156}$; de hecho, la escritura estipula que Arcís Martí podía abandonar este oficio por otro. La importancia económica de esta manufactura se reafirma cuando se estipula que si Martí ejercía su derecho a cambiar de actividad, el empresario debía saberlo con la suficiente antelación, unos dos meses, para poder buscar a otro artesano y así evitar la pérdida económica por la inactividad en el obraje. Es una disposición lógica, si tenemos en cuenta que los vidrieros no abundaban en la Ciutat de Mallorca y que el horno no se apagaba durante el período anual de funcionamiento, y por tanto se consumía una gran cantidad de combustible, encareciendo todo el proceso de elaboración.

La última estructura de organización contractual es la sociedad, un sistema "precapitalista", en el que, según el caso, el propietario aporta el capital, las materias primas e incluso el procedimiento de distribución de la producción $^{157}$. Los ejemplos de estos pactos son frecuentes en el arte del vidrio para este periodo en otras zonas de Europa y, también, en Cataluña ${ }^{158}$. Se pueden distinguir tres tipos de asociaciones en relación al perfil de los contratantes según las fuentes documentales. En primer lugar, la formada por maestros vidrieros y personas ajenas a la profesión. En segundo, la constituida por vidrieros y marchantes del producto. Finalmente, aquellas que han sido fundadas exclusivamente por vidrieros. En cuanto a Mallorca, el único ejemplo corresponde a la establecida hacia el año 1394 entre Nicolau Coloma y Julià Martí, vidrieros. Las capitulaciones exactas de esta compañía las desconocemos al no haber localizado la escritura de creación, la noticia la debemos a un pedido de materiales para el horno que ambos habían realizado, como ya hemos comentado.

155 M.A. Capellà, El vidre a Mallorca, p. 921, doc. 30; R. Rosselló, J. Bover, Els vidriers de Mallorca, pp. 496, 505-506.

156 Arcís Martí murió tres años después. Este linaje está vinculado a otros vidrieros activos en la ciudad, como sabemos por la talla de 1478. No obstante, parece claro que esta familia no tenía instalación propia, sino que vivía de arrendar su arte. Esta afirmación se vería corroborada cuando en 1485 la viuda colocó a su hijo para aprender el oficio de tejedor de lana (R. Rosselló, J. Bover, Els vidriers de Mallorca, p. 497).

157 D. Foy, L'accés aux matières, pp. 114-115; D. Foy, Les verriers provençaux, pp. 596-597.

158 D. Foy, Le verre médiéval, pp. 82-83; D. Stiaffini, Il vetro nel medioevo, pp. 86-87; F. D'Angelo, La produzione del vetro a Palermo, pp. 107-116. 


\section{CONCLUSIÓN}

El estudio del caso de Mallorca demuestra que, a pesar de no ser un centro puntero, fue una área de irradiación de las influencias de las manufacturas catalanas que marcaron el devenir del vidrio de consumo y artístico en la Baja Edad Media peninsular ${ }^{159}$. Las dimensiones territoriales y la población comportaron un desarrollo restringido de esta artesanía, aunque perfectamente conectado mediante las redes marítimas con los focos más influyentes. La movilidad de artífices y la llegada de obras importadas, como en otras artes decorativas medievales, facilitaron la transmisión de técnicas y estilos. El número de hornos abiertos simultáneamente en la ciudad es limitado, oscilando entre una o dos infraestructuras bien documentadas, pero determinados datos permiten intuir la existencia de algún otro obrador. En este sentido, esta situación sería relativamente equiparable a la de Barcelona, donde se constata la exclusividad en la fabricación en un único taller ${ }^{160}$.

El artesanado se consolidó, después de varios intentos frustrados, a finales del siglo XIV con la irrupción de dos importantes castas de vidrieros de origen catalán: los Coloma y los Sala. Esta última familia, junto con los Xatart, dominó la producción en la Ciutat de Mallorca hasta los primeros años del siglo XVI, momento en que perdió el control del sector. El XVI supuso, al menos durante la primera mitad, la sustitución del modelo parentelar por el de las sociedades formadas por vidrieros, tenderos y miembros del estamento militar local, en un contexto caracterizado por la difusión y éxito de los objetos artísticos de la vidriería catalana y veneciana ${ }^{161}$.

\section{BIBLIOGRAFÍA CITADA}

À travers le verre du moyen âge à la renaissance, cat. exp., Ruan, Musées départementaux de la Seine-Maritime, 1989.

Aguiló, Estanislau de K., Documento sobre la fabricación de vidrio en Mallorca (1398), "Bolletí de la Societat Arqueològica Lul-liana" 3 (1889-1890), p. 88.

Aguiló, Estanislau de K., Industrias mallorquinas. Fábricas de cinabrio y de vidrio (1347), "Bolletí de la Societat Arqueològica Lul·liana" 3 (1889-1890), pp. 318-320.

159 I. Domènech, El vidre d'ús i de prestigi, p. 185.

160 S. Cañellas, C. Domínguez, Els forns de vidre a Barcelona, p. 633.

161 M.A. Capellà, Societats vidrieres, p. 57. 
Ainaud de Lasarte, Juan, Cerámica y vidrio, Ars Hispaniae, Madrid, Plus Ultra, 1952.

Aldeguer Gordiola, Daniel, Artesanía del vidrio en Mallorca, Palma, 1949.

Almela y Vives, Francisco, La antigua industria del vidrio en Valencia, Valencia, Feriario, 1954.

Amouric, Henri; Foy, Danièle, Notes sur la production et la commercialisation de la soude dans le midi méditerranéen du XIIIe au XVIIIe siècle, en Histoire des techniques et sources documentaires, Méthodes d'approche et expérimentation en région méditerranéenne, Actes du Colloque du G.I.S., Aix-en-Provence, 1981, pp. 157-172.

Amouric, Henri; Foy, Danièle, De la salicorne aux soudes factices; mutations techniques et variation de la demande, en L'évolution des techniques est-elle autonome?, Aix-en-Provence, Publications de l'Université de Provence Marseille-Aix 1, 1991, pp. 39-75.

Barceló Crespí, Maria, Ciutat de Mallorca en el trànsit a la Modernitat, Palma, Institut d'Estudis Baleàrics, 1988.

Barceló Crespí, Maria; Rosselló Bordoy, Guillem, Terrissa. Dades documentals per a l'estudi de la ceràmica mallorquina del segle XV, Palma, Canon editorial, 1996.

Barceló Crespí, Maria; Rosselló Bordoy, Guillem, La ciudad de Mallorca. La vida cotidiana en una ciudad mediterránea medieval, Palma de Mallorca, Lleonard Muntaner, 2006.

Bernat i Roca, Margalida, La manufactura del sabó. Nòtules per al seu estudi, en La manufactura urbana i els menestrals (ss. XIII-XVI). IX Jornades d'Estudis Històrics Locals, Palma, Institut d'Estudis Baleàrics, 1991, pp. 235-245.

Bernat i Roca, Margalida, El call de ciutat de Mallorca. A l'entorn de 1350, Palma, Lleonard Muntaner, 2005.

Bernat i Roca, Margalida; Serra i Barceló, Jaume, El forn de vidre del carrer de Can Burgos: nòtules per a l'estudi del vidre medieval i post-medieval a Mallorca, "Bolletí de la Societat Arqueològica Lul·liana" 48 (1992), pp. 91-113.

Bonafè Barceló, Francesc, Flora de Mallorca, Mallorca, Editorial Moll, 1978, vol. II.

Cabanes Pecourt, M. Desamparados, El "morabatí" de 1390 en la parroquia de San Miguel, "Estudis Baleàrics" 28 (1988), pp. 73-82.

Camiade, Martine; Fontaine, Denis, Verreries et verriers catalans, Perpiñán, Sources, 2006.

Campaner, Álvaro, Cronicón Mayoricense, Palma de Mallorca, Luis Ripoll, 1984 (1886). 
Canyelles, Agustí, Tall per una armada de corsari 1449, "Bolletí de la Societat Arqueològica Lul·liana" 24 (1932), pp. 8-22.

Cañellas i Martínez, Sílvia; Domínguez Rodés, M. Carme, Els forns de vidre a Barcelona i la seva rodalia (segles XIV-XVI), "Anuario de Estudios Medievales" 38/2 (2008), pp. 611-637.

Cañellas i Martínez, Sílvia; Domínguez Rodés, M. Carme, Intervenció de les institucions públiques en la producció de vidre a la ciutat de Barcelona (segles XIV-XVI), en La ciutat en xarxa. XIè Congrés d'Història de Barcelona, Barcelona, Arxiu Històric de la Ciutat de Barcelona - Institut de Cultura - Ajuntament de Barcelona, 2009, pp. 1-15.

Capellà Galmés, Miquel Àngel, El vidre a Mallorca entre els segles XIV $i$ XVIII, Palma, Universitat de les Illes Balears, Departament de Ciències Històriques i Teoria de les Arts, 2009, (tesis doctoral).

Capellà Galmés, Miquel Àngel, Societats vidrieres i braç noble durant la primera meitat del segle XVI, "Memòries de la Reial Acadèmia Mallorquina d'Estudis Genealògics, Heràldics i Històrics" 21 (2011), pp. 45-62.

Capellà Galmés, Miquel Àngel, L'activitat de vitrallers $i$ vidriers de buf a l'arquitectura gòtica. Relacions i influències a la Ciutat de Mallorca, "Bolletí de la Societat Arqueològica Lul-liana" 67 (2011), pp. 137-158.

Carrere, Claude, Barcelone, centre économique à l'époque des difficultés, 1380-1462, París - La Haya, Éditions EHESS, 1967.

Cateura Bennàsser, Pau, El Regne Esvaït: desenvolupament econòmic, subordinació política i expansió fiscal (Mallorca, 1300-1335), Mallorca, El Tall, 1998.

Cateura Bennàsser, Pau, La trentena esgarrifadora. Guerra i fiscalitat. El Regne de Mallorca (1330-1357), Palma, El Tall, 2000.

Chambon, Raymond, Esquisse de l'évolution des creusets de verrerie de l'Antiquité à la Renaissance, en Annales du ler Congrès des Journées Internationales du Verre, Lieja, 1958, pp. 115-117.

Charleston, R. J., Glass furnaces through the ages, "Journal of Glass Studies" 20 (1978), pp. 9-25.

Cressier, Patrice (ed.), El Vidrio en Al-Andalus, Madrid, Casa de Velázquez Fundación Nacional Centro del Vidrio, 2000.

D’Angelo, Francesco, La produzione del vetro a Palermo. Materie prime locali e maestranze toscane, en Mendera, Marja (ed.), Archeologia e storia della produzione del vetro preindustriale, Florencia, Università di Siena, 1991, pp. 107-116.

Domènech i Vives, Ignasi, El vidrio, en Bartolomé Arraiza, Alberto (coord.), Las Artes Decorativas en España, Summa Artis, Madrid, EspasaCalpe, 1999, vol. XLV-1. 
Domènech i Vives, Ignasi, El vidre d'ús i de prestigi, en L'Art Gòtic a Catalunya. Arts de l'Objecte, Barcelona, Enciclopèdia Catalana, 2008, pp. 181-207. Domínguez Rodés, M. Carme; Cañellas i Martínez, Sílvia, El forn de vidre del Pla d'en Llull de Barcelona (1447-1640) en els protocols notarials, "Estudis històrics i documents dels arxius de protocols" 23 (2005), pp. 141-172.

Durliat, Marcel, L'art en el Regne de Mallorca, Palma, Editorial Moll, 1964. Ensenyat y Pujol, Juan B., Historia de la Baronía de los señores obispos de Barcelona en Mallorca, Mallorca, 1983 (1919).

Foy, Danièle, Les verriers provençaux à la fin du Moyen Âge, en Barral i Altet, Xavier (coord.), Artistes, artisans et production artistique au Moyen Âge, París, Picard, 1986, vol. I, pp. 591-599.

Foy, Danièle, Le verre médiéval et son artisanat en France méditerranéenne, París, CNRS, 1988.

Foy, Danièle, L'accès aux matières premières du verre, en Amouretti, MarieClaire; Comet, Georges (coord.), Artisanat et matériaux: la place des matériaux dans l'histoire des techniques, Aix-en-Provence, Publications de l'Université de Provence, 1998, pp. 101-125.

Foy, Danièle, Technologie, géographie, économie. Les ateliers de verriers primaires et secondaires en Occident, esquisse d'une évolution de l'Antiquité au Moyen-Âge, en Nenna, Marie-Dominique (coord.), La route du verre. Ateliers de verriers primaires et secondaires du second millénaire av. J.-C. au Moyen Âge, Lion, Maison de l'Orient Méditerranéen, 2000, pp. 147-170.

Foy, Danièle, Recyclages et réemplois dans l'artisanat du verre. Quelques exemples antiques et médiévaux, en Ballet, Pascale; Cordier, Pierre; Dieudonne-Glad, Nadine (coord.), La ville et ses déchets dans le monde romain. Rebuts et recyclages, Montagnac, Monique Mergoil, 2003, pp. 271-276.

Foy, Danièle; Amouric, Henri, Les artisanats de la céramique et du verre en Provence: la question du combustible au Moyen-Âge et à l'époque moderne, en Protoindustries et histoire des forêts, Toulouse, Groupement de Recherche ISARD - CNRS, 1992, pp. 45-61.

Frothingham, Alice Wilson, Hispanic Glass. With examples in the Collection of The Hispanic Society of America, Nueva York, The Hispanic Society of America, 1941.

Frothingham, Alice Wilson, Spanish Glass, Londres, Faber and Faber, 1964.

García, Manuel E., Carta sobre el cultivo y provechos de las barrillas, "Semanario de Agricultura y Artes" 105 (1799), pp. 1-11.

Gasparetto, Astone, Il vetro di Murano dalle origini ad oggi, Venecia, Neri Pozza Editore, 1958. 
Gil Olcina, Antonio, Explotación y cultivo de las plantas barrilleras en España, "Estudios geogràficos" 138-139 (1975), pp. 453-478.

Giménez Raurell, M. Cristina, El vidrio soplado en Mallorca, Barcelona, Institut Balear de Disseny, 1996.

Gran Enciclopèdia de Mallorca, Palma, Promomallorca, 1989-1997, vol. XIII.

Gratuze, Bernard; Soulier, Isabelle; Barrandon, Jean-Noël; Foy, Danièle, The origine of cobalt blue pigments in french glass from the thirteenth to the eighteenth centuries, en Trade and discovery: the scientific study of artefacts from post-medieval Europe and Beyond, Londres, British Museum Press, 1995, pp. 123-133.

Gudiol Ricart, Josep, Els vidres catalans, Barcelona, Alpha, 1936.

Jiménez Castillo, Pedro; Muñoz López, Francisco; Thiriot, Jacques, Les ateliers urbains de verriers de Murcia au XIIe siècle, en Pétrequin, Pierre; Fluzin, Philippe; Thiriot, Jacques (ed.), Arts du feu et productions artisanales, Antibes, APDCA, 2000, pp. 433-452.

Llompart Moragues, Gabriel, Plata medieval mallorquina, "Bolletí de la Societat Arqueològica Lul-liana" 39 (1982), pp. 51-92.

Llompart, Gabriel, Botiguers i quincallaires a la pagesia de la Mallorca medieval, "Bolletí de la Societat Arqueològica Lul-liana" 52 (1996), pp. 179-208.

Llompart, Gabriel, País, paisatge i paisanatge a la taula de Sant Jordi de Pere Niçard, en El cavaller i la princesa. El Sant Jordi de Pere Nisard i la Ciutat de Mallorca, Palma de Mallorca, Consell de Mallorca - Sa Nostra, 2001, pp. 58-89.

Mannoni, Tiziano; Giannichedda, Enrico, Arqueología de la producción, Barcelona, Ariel, 2004.

Miralles i Montserrat, Joan, Corpus d'antropònims mallorquins del segle XIV, Barcelona, Institut d'Estudis Catalans, 1977.

Moretti, Cesare, Glossario del vetro veneziano, dal Trecento al Novecento, Venecia, Marsilio, 2002.

Oliver Castaños, Anna, El taller de vidre medieval de Sant Fost de Campsentelles, "Acta historica et archaeologica Mediaevalia" 10 (1989), pp. 387-426.

Philippe, Michel, Naissance de la verrerie moderne (XIIe-XVIe siècles), Turnhout, Brepols Publishers, 1998.

Planell, Leopoldo, Vidrio: Historia, tradición y arte. Historia del Gremio de Vidrieros de Luz y Soplo de Barcelona, desde los orígenes hasta el primer tercio del siglo XX, Barcelona, Emporium, 1948, vol. I-II.

Quadrado, Josep Maria, Privilegios y Franquicias de Mallorca, Palma, Govern de les Illes Balears, 2002. 
Quetglas Gayá, Bartolomé, Los gremios de Mallorca. Siglos XIII al XIX, Palma, Cort, 1980 (1939).

Riera Frau, M. Magdalena, Història de Cabrera. Comentaris a una cronologia, en Pons Valens, Joan Manuel; Riera Frau, M. Magdalena; Riera Rullan, Mateu, Història i arqueologia de Cabrera, Palma, Ajuntament de Palma, 2001, pp. 45-63.

Riu de Martín, M. Carmen, El treball artesà a Barcelona els segles XIV al XVI segons les ordinacions gremials: els esparters $i$ vidriers, "Acta historica et archaeologica mediaevalia" 23-24 (2002-2003), pp. 551-556.

Riu de Martín, M. Carmen, Ceramistas y vidrieros de Barcelona a través de los testamentos: aspectos socioeconómicos, siglos XV-XVII, "Estudis Històrics i Documents dels Arxius de Protocols" 21 (2003), pp. 227-266.

Riu de Martín, M. Carmen, Onomástica y localización de algunos ceramistas y vidrieros barceloneses de los siglos XIV al XVII, "Acta historica et archaeologica mediaevalia" 25 (2003-2004), pp. 1045-1069.

Riu de Martín, M. Carmen, Vida cotidiana de los ceramistas y vidrieros barceloneses, "Anuario de Estudios Medievales" 34/1 (2004), pp. 307-355.

Riu de Martín, M. Carmen, La manufactura del vidrio y sus artífices en la Barcelona bajomedieval, "Anuario de Estudios Medievales" 38/2 (2008), pp. 585-609.

Rosselló Lliteras, Juan, El convento de Santo Domingo de Mallorca (s. XIIIXV), "Bolletí de la Societat Arqueològica Lul·liana" 41 (1985), pp. 115-130.

Rosselló, Ramon, Aportació a la història medieval de Menorca (segle XIV), Menorca, Consell Insular de Menorca, 1985.

Rosselló, Ramon; Albertí, Jaume, Història de Banyalbufar. Segles XIII-XVI, Palma, Lleonard Muntaner, 1995.

Rosselló, Ramon; Bover, Jaume, La fabricación de la sosa en Mallorca: una aportación árabe, "Kasbah" 4 (1993), pp. 28-29.

Rosselló Vaquer, Ramon, Notes històriques de Cabrera, Campos, Edicions Roig i Montserrat, 1995.

Rosselló Vaquer, Ramon; Bover Pujol, Jaume, Els vidriers de Mallorca. Segles XIV-XVI, en Transferències i comerç de ceràmica a l'Europa mediterrània (segles XIV-XVII). XV Jornades d'Estudis Històrics Locals, Palma, Institut d'Estudis Baleàrics, 1997, pp. 493-510.

Rosselló Vaquer, Ramon; Bover Pujol, Jaume, Els vidriers de Mallorca. Segles XIV-XVI. Segona part, "Bolletí de la Societat Arqueològica Lul-liana" 53 (1997), pp. 409-416.

Sanchis Guarner, Manuel, El arte del vidrio en Mallorca. Panorama Balear, Palma, Luis Ripoll, 1952. 
Santamaría, Álvaro, La formación profesional en Mallorca en la época de Fernando el Católico, en La Corona d'Aragona e il Mediterraneo. Aspetti e problemi comuni da Alfonso il Magnanimo a Ferdinando il Cattolico: 1416-1516. IX Congrés d'Història de la Corona d'Aragó, Nápoles, Società Napoletana di Storia Patria, 1973, vol. I, pp. 257-281.

Santaner Marí, Juan, Historia del arrabal de Santa Catalina, Mallorca, Parroquia Inmaculada Concepción, 1967.

Sastre i Barceló, Joan Carles, Espiritualitat $i$ vida quotidiana al Monestir de Santa Clara. Ciutat de Mallorca. Segles XIII-XV, Palma de Mallorca, Lleonard Muntaner, 2006.

Stiaffini, Daniela, Il vetro nel medioevo. Techniche, strutture, manufatti, Roma, Fratelli Palombi, 1999.

Vaquer Bennasar, Onofre, L'esclavitud a Mallorca. 1448-1500, Palma de Mallorca, Institut d'Estudis Baleàrics, 1997.

Vaquer Bennasar, Onofre, El comerç marítim de Mallorca 1448-1531, Mallorca, El Tall, 2001.

Vaquer, Onofre, El contrato de trabajo en la Mallorca medieval. Aprendices, criados y obreros en el siglo XV, "Mayurqa" 22/1 (1989), pp. 645654.

Vaquer, Onofre, Immigrants a Mallorca a la segona meitat del segle XV, "Bolletí de la Societat Arqueològica Lul·liana" 51 (1995), pp. 125-140.

Vaquer, Onofre, Immigrants a Mallorca a la segona meitat del segle XV, "Bolletí de la Societat Arqueològica Lul-liana" 55 (1999), pp. 353-362.

Vaquer, Onofre, Immigrants a la Ciutat de Mallorca. 1448-1598, en El món urbà a la Corona d'Aragó del 1137 als decrets de Nova Planta, Actes del XVII Congrés d'Història de la Corona d'Aragó, BarcelonaPoblet-Lleida, Barcelona, Universitat de Barcelona, 2003, vol. II, pp. 445-455.

Vibot, Tomàs, Son Bunyola. Una mar de noms. Història i toponímia d'una possessió de mar, Banyalbufar, Associació Cultural Bany-Al-Bahar, 1999.

Zaforteza y Musoles, Diego, La Ciudad de Mallorca: ensayo histórico-toponímico, Palma de Mallorca, Ajuntament de Palma, 1987, vol. I-V.

Fecha de recepción del artículo: julio 2012

Fecha de aceptación y versión final: enero 2013 